\title{
Vegetation Response to Climate and Climatic Extremes in Northwest Bangladesh: A Quantile Regression Approach
}

Mohammad Ahsan Uddin

University of Dhaka

A S M Maksud Kamal ( $\sim$ maksudkamal@du.ac.bd)

University of Dhaka Faculty of Earth and Environmental Sciences https://orcid.org/0000-0002-38962032

\section{Shamsuddin Shahid}

Universiti Teknologi Malaysia (UTM)

\section{Research Article}

Keywords: Normalized difference vegetation index, rainfall, temperature, quantile regression, trend analysis

Posted Date: August 17th, 2021

DOI: https://doi.org/10.21203/rs.3.rs-718383/v1

License: (c) (i) This work is licensed under a Creative Commons Attribution 4.0 International License. Read Full License

Version of Record: A version of this preprint was published at Theoretical and Applied Climatology on February 24th, 2022. See the published version at https://doi.org/10.1007/s00704-022-03968-y. 


\section{Abstract}

The present study assessed the vegetation response to climate in the water-stressed northwest Bangladesh (NWB). The quantile regression analysis was employed to evaluate the effect of climate and climatic extremes on vegetation. The nonparametric correlation analysis was used to assess the climatic influence on vegetation for various time lags. Besides, the modified Mann-Kendall (MMK) test was conducted to understand the changes in climate and vegetation to anticipate the climate change impacts on vegetation. Satellite estimation of Normalized Difference Vegetation Index (NDVI) and observed rainfall and temperature data collected from five locations of the study area for the period 1982-2018 was used for this purpose. The results revealed a negative effect of rainfall, a positive impact of maximum temperature on vegetation in monsoon and a positive influence on minimum temperature on vegetation in winter. Quantile regression analysis revealed a significant negative influence of extreme rainfall and a positive impact of maximum temperature on vegetation for the whole NWB. Overall, the study revealed a greater influence of temperature than rainfall on vegetation change in the region. The trend analysis revealed a reduction in rainfall $(-2.56 \mathrm{~mm} /$ decade) and a rise in temperature $\left(0.176^{\circ} \mathrm{C} /\right.$ decade $)$, and thus, an increase in vegetation ( 0.014 per decade). The results indicate the positive effect of climate change on vegetation, positively impacting the environment and water resources in the study area.

\section{Introduction}

Climate variability, particularly changes in precipitation and temperature, are the major factors that regulate plants composition and growth (Zhang et al., 2021). A lack of precipitation or high precipitation and high or low temperature affects vegetation growth and vegetation covers (Cao et al., 2021; AlmeidaÑauñay et al., 2021; Mishra et al., 2021). Increased climate variability due to global warming also has significant implications on vegetation dynamics (Zhang et al., 2021; Li et al., 2021; Buditamaet al., 2021). Therefore, climatic indices are widely used for understanding the possible changes in vegetation due to climate variability and extremes (Wang et al., 2021; Yan et al., 2021; Zahoor et al., 2021). Globally $64 \%$ of changes in vegetation are due to climate variability (Luo et al., 2021). Vegetation changes also provide vital information on how terrestrial ecosystems may affect climate (Pour et al., 2020). Therefore, the vegetation-climate nexus provides vital information on climate change and bio-environmental vulnerability for strategies mitigation planning (Measho et al., 2021; Wang et al., 2021; Khwarahm et al., 2021).

Normalized Difference Vegetation Index (NDVI) provides an estimation of earth surface vegetation conditions. It has been extensively employed for monitoring spatial and temporal changes in vegetation across the globe (Pan et al., 2019; Measho et al., 2021; Wang et al., 2021). NDVI estimated using satellite sensors allows monitoring vegetation over a large area, and therefore, its role in vegetation and environmental monitoring and assessment in multiple time scales is well established (Liu et al. 2015; Hou et al., 2015; Lamchin et al., 2020). Climate change impacts on vegetation dynamics are very slow, and therefore, often difficult to decipher. However, it causes significant changes in vegetation distribution over 
a longer period. The availability of satellite NDVI data for a longer period allows vegetation changes assessment at global, regional and local scales (Measho et al., 2021). In the last three decades, it has been utilized for monitoring crop yield (Mkhabela et al., 2011), biodiversity (Madonsela et al., 2018), environmental degradation (Zhang et al., 2021), vegetation dynamics (Zarei et al., 2020), forest fire susceptibility (Van Le et al., 2021), biological productivity (Alhumaima and Abdullaev, 2020), ecological environment (Sun et al., 2021), desertification (Li et al., 2021). Besides, it has been used to examine the influence of climate variability on vegetation dynamics, droughts and environmental sustainability (Parmesan, C. 2006, Walther et al. 2002, Bi et al. 2013, Jiang et al. 2017, Qi et al. 2019; Zhu et al. 2019).

The studies suggest complexity in climate-vegetation nexus, as it depends on many other factors like vegetation type, growth status, soil texture, water sources availability, and an area's existing environment. For example, high rainfall causes flood and vegetation reduction in flood-prone regions. Groundwater use for irrigation during low rainfall increases vegetation cover in irrigated agriculture-dominated regions. Therefore, the relation of NDVI with rainfall highly dependent on the existing setup of an area (Liu et al. 2015; Li et al. 2018). Similarly, vegetation's relationship with the temperature significantly differs for cold and warm climate regions (Tan et al., 2015).

The climate-vegetation relationship is much more complex in the areas where human activities influence surface water hydrology. The ecology of northwest Bangladesh (NWB) is different from others (Shahid, 2008). The spatial variability of rainfall and temperature in the region is higher compared to other parts. The region also experiences climatic extremes, particularly temperature extremes. The temperature during winter goes below $10^{\circ} \mathrm{C}$ and rises to $40^{\circ} \mathrm{C}$ during summer. The vegetation characteristic of the region is different from other regions of the country due to different climates. Overall, the region is highly potential for agriculture. A major portion of the crop in the country is grown in the region (Shahid and Hazarika, 2010). However, water availability in most parts of the region is less compared to other regions.

Less rainfall and reduction of river flow make NWB dry during non-monsoon months. Groundwater is used to supplement the reduction of surface water availability. However, a large abstraction of groundwater during the dry season declines groundwater levels in the region. The variation of water available and water sources during the different seasons has made its vegetation dynamic highly complex. The NWB is also one of the most vulnerable regions of this most vulnerable country in the world. Studies reported several implications of rising temperature and rainfall changes on water resources, agriculture, environment and people's livelihood in the region (Shahid, 2011). Assessment of climatic influence on vegetation is complicated to decipher in the area. However, vegetation plays a vital role in ecology and the environment, affecting people's livelihood and economy. Studies for an understanding of vegetation dynamics is still inadequate in the region.

Generally, different kinds of correlation and regression analyses are used to assess the nexus between climate and vegetation. In literature, the association of vegetation with climatic variables has been estimated different methods, including anomaly analysis (Zhao et al., 2018), Pearson correlation 
analysis (Buditama et al., 2021), partial correlation analysis (Yan et al., 2021), Time lag cross-correlation method (Wang et al., 2021), geographical detector method (Zhao et al., 2021), residual trend analysis (Ge et al., 2021), Recurrence Plots (Almeida-Ñauñay et al., 2021), Spearman rank correlation (Alhumaima and Abdullaev, 2020),Multiple wavelet coherence (Cheng et al., 2021), coefficient of variation model (Sun et al., 2021),and principal components regression (You et al., 2021). The impact of climate variables on vegetation has been quantified using varieties of regression methods, including simple linear regression (Li et al., 2021) and least absolute shrinkage and selection operator logistic regression (Wang et al., 2021). Besides, machine learning methods have been employed to model the climatic impacts on vegetation, like classification and regression trees (Cao et al., 2021) and deep learning algorithms (Chen et al., 2021). The studies showed that machine learning can delineate vegetation sensitivity's complex nature to the climate that is not possible using conventional statistical methods. However, the machine learning methods provide a black-box model, which is not possible to understand the physical process responsible for vegetation changes.

The parametric and nonparametric analysis methods used so far for climate-vegetation relationship analysis only indicates the relationship in the mean behaviour of climate and vegetation. It cannot inform the tail relationships, particularly when the data distribution is not normal (Kuan, 2007). However, such information is important to understand the effect of extreme climate on vegetation. This emphasizes assessment of climate-vegetation nexus across the entire distribution. Such assessment can explain how the changes in lower and higher quantiles of rainfall (probable droughts or floods) may affect vegetation. The quantile regression (QR) (Koenker and Bassett 1978; Koenker 2005) can be used to assess the relationship between two variables for different quantiles (Hagfors et al., 2016). Therefore, it can provide a more comprehensive statistical examination of relationships. The QR is a nonparametric approach independent of data distribution. The applicability of the method to different distributions of data has increased its applications in various climatological studies in recent years (Sa'adi et al., 2017; Khan et al., 2019; Mohsenipour et al., 2020; Treppiedi et al., 2021; Yoshida, 2021; Kim et al., 2021; Pumo and Noto, 2021).

The present study aims to assess the influences of major climate variables, rainfall, maximum and minimum temperature on vegetation dynamics of NWB. Besides, the trends in climate and NDVI are estimated to anticipate the possible changes in vegetation in annual and seasonal scales. The study's findings would provide valuable information on climate change adaptation to sustain the environment and the betterment of people.

\section{Geography And Climate Of Northwest Bangladesh}

The NWB is selected for the present study since it is the most water-stressed region in the country. The region is bounded by the two major rivers, the Jamuna in the east and the Ganges in the south. Out of eight hydrological units of Bangladesh, the NWB has the most extreme climate. Due to its subtropical location, temperature variations are more pronounced in NWB. The study area covers $34,359 \mathrm{~km}^{2}$. Fig. 1 shows the NWB on the map of Bangladesh. 
The rainfall in the study area is highly seasonal. It varies from more than $350 \mathrm{~mm}$ in July to near zero in December and January (Fig. 2). The daily maximum temperature in NWB ranges between $25.4^{\circ} \mathrm{C}$ in January and $35.9^{\circ} \mathrm{C}$ in April and the minimum temperature between $10.2^{\circ} \mathrm{C}$ in January and $26.2^{\circ} \mathrm{C}$ in August. The NWB experiences four distinct seasons, winter (Dec-Feb), pre-monsoon (Mar-May), monsoon (Jun-Sep) and post-monsoon (Oct-Nov) (Pour et al., 2018). The rainfall variability among the seasons is high. More than $62 \%$ of the annual total rainfall occurs in the monsoon and merely $4 \%$ in winter.

The topography of the region is very flat, with a mild declining slope from the north $(\sim 100 \mathrm{~m})$ to the south $(<10 \mathrm{~m})$, except for a small elevated area in the southwest (Fig. 3a). The climate in the region has a significant geographical variability (Fig. 3b). The southern part, particularly the southwest region, receives the lowest $(1600 \mathrm{~mm})$, and the northern region gets the highest rainfall $(2400 \mathrm{~mm})$. The daily mean temperature distribution follows an opposite pattern of rainfall. It is relatively less in the north $\left(<24.8^{\circ} \mathrm{C}\right)$ and high in the south $\left(>26.6^{\circ} \mathrm{C}\right)$. Year to year rainfall variability in NWB is significant, and therefore, the region experiences frequent droughts (Shahid, 2008).

\section{Data And Methods}

\subsection{Data and sources}

Daily rainfall, maximum temperature and minimum temperature data from five locations of the study area, as shown in Fig. 3(a), were collected from the Bangladesh Meteorological Department. The Normalized Difference Vegetation Index (NDVI) data were derived from the Terra Moderate Resolution Imaging Spectroradiometer (MODIS) Vegetation Indices (MOD13Q1) Version 6, which was collected for the years 1982-2018. The data is freely available from (https://lpdaacsvc.cr.usgs.gov/appeears/).

Several missing records were noticed in observed meteorological data. However, the missing data were random. The missing data at a station was filled through interpolation of data of the nearby gauge location. The homogeneity of the climate data was evaluated using sequential t-test tests. Data at all the stations were found homogeneous at a significance level of 0.05 .

\section{Methods}

The trends in climate and vegetation in the study area was estimated using the modified Mann-Kendall (MK) test and Sen's slope estimator (SSE). The nonparametric Spearman correlation was used to assess the relation climatic variables with NDVI. The relations were estimated for annual, seasonal and monthly scales. Besides, the relation was explored for different monthly lag periods. Finally, the quantile regression was used to assess the relation of climate variables with different quantiles of NDVI. Details of the methods are provided below.

4.1 Trend analysis 
Sen's slope estimator (SSE) is a nonparametric method that estimates the change over time in data (Sen, 1968). It estimates the change as the median of all slopes calculated for two successive data points.

The MK is a nonparametric test used for any distributed data (Kendall, 1975; Mann, 1945). It provides two measures, significant level and sign; the former shows the strength while the latter indicates to change direction. You et al. (2002) improved the MK test to remove the impacts of autocorrelation in data, commonly noticed in hydrological series. In this study, the modified MK test (MMK) was used to estimate the significance of the change estimates using SSE. Different recently published articles provide details of MMK test (Nashwan et al., 2019).

\subsection{Spearman rank correlation}

The non-parametric SCC was used to estimate the relationship of NDVI with rainfall and temperature, considering the skewed distribution of rainfall and NVDI. The SCC between two variables $a$ and $b$ can be estimated as,

$$
r_{s}=1-\frac{6 \sum d^{2}}{n\left(n^{2}-1\right)}
$$

where $\mathrm{d}$ is the difference between the ranks of $a$ and $b$, and $n$ is the sample size.

\subsection{Estimation of lag relationships}

The impacts of cumulative rainfall and temperature for different lags were evaluated for a better understanding of the relationship of NDVI with climate variables. The relationships were estimated for one to three months lags and cumulative rainfall or temperature for one to three months lags. The estimation of the relation for various lags and cumulative lags are presented in Fig. 4. For example, the NDVI of June was correlated with rainfall or temperature of May to evaluate the one-month lag relationship, rainfall or temperature of April for the two-month lag relationship and so on. To evaluate the one-month cumulative lag relationship, April and May's cumulative rainfall or temperature was correlated with the NDVI of June. Similarly, March-May's cumulative rainfall or temperature was correlated with NDVI of June to assess the two-month cumulative lag relationship.

\subsection{Quantile Regression}

The QR is first proposed by Koenker and Bassett (1978). The mathematical expression of QR is presented in Eq. (2):

$$
y_{q}=a_{q}+b_{q} x+\varepsilon_{q}
$$

where $y$ is the dependent variable (NDVI in the present study), and $x$ represent rainfall or temperature, $q$ are the quantiles (any value between 0 and 1 ), $a_{q}$ and $b_{q}$ are QR factors obtained by minimizing the summation of asymmetrically weighted absolute deviations, 


$$
\min \sum_{i: y_{i} \geq a_{q}+b_{q} x_{i}} q\left|y_{i}-a_{q}-b_{q} x_{i}\right|+\sum_{i: y_{i}<a_{q}+b_{q} x_{i}}(1-q)\left|y_{i}-a_{q}-b_{q} x_{i}\right|
$$

The $q$ values used in this study ranged from 0.01 to 0.99 with a step of 0.01 . The magnitude and sign of $\mathrm{b}_{\mathrm{q}}$ indicate the amount and direction of NDVI change due to changes in rainfall or temperature for different quantiles. The significance of $b_{q}$ was estimated to assess the relationship for different quantiles at a level of 0.05 .

\section{Results}

\subsection{Spatial distribution of seasonal NDVI}

The geographical variability of mean NDVI in the study area for the period 1982-2018 for different seasons are presented in Fig. 5. The NDVI ranges from -1 to +1 is presented as a colour ramp in the Figure. The vegetation can be classified according to NDVI. The NDVI values between 0.226 and 0.37 correspond to areas with sparse vegetation. The NDVI in moderate vegetation areas tends to vary between 0.37 and 0.51 , and the NDVI above 0.51 indicates a high density of green leaves. The Figures show a large seasonal and spatial variability of vegetation in the study area. The highest NDVI was noticed in post-monsoon, followed by the monsoon, pre-monsoon and winter. The least NDVI during winter is due to almost no rainfall during this season in the study area. The rainfall is also less during premonsoon, and therefore, less vegetation. The proliferation of vegetation occurs post-monsoon after the area receives high rainfall in monsoon.

The soil and landuse of an area significantly affect the NDVI of a region. The maps showing the spatial distribution of soil and landuse of the study area are shown in Figs. 6(a) and (b), respectively. The spatial distribution of NDVI in Fig. 5 shows less vegetation along the riverbank in the east and the south. Overall, the NDVI is less over the soil with less moisture-holding capacity $(<200 \mathrm{~mm})$. Therefore, the NDVI is relatively less in the south compared to the north. However, pre-monsoon showed the opposite scenario due to irrigated rice cultivation in the region.

\subsection{Trends in climate and NDVI}

The monthly time series of areal average rainfall, average temperature and NDVI of the study area are presented in Fig. 7. The Figure shows a reduction of extreme monsoon rainfall in the region. Therefore, a reduction in peak rainfall was noticed with time. This indicates a reduction of rainfall variability in the study area. The daily mean temperature, presented in Fig. 7(b), shows variability in monthly average temperature in the region between 16 and $31^{\circ} \mathrm{C}$. The temperature time series shows a gradual increase in temperature in the warmest and the coldest months in the region. This caused a gradual increase in mean temperature in the study area. The monthly NDVI showed a large fluctuation over a short period. Overall, it varies between 0.05 and 0.3 , except in few exceptional cases. The average NDVI was negative in two cases, which is due to floods in those months. NDVI showed a gradual increase over time in the 
study area. The NDVI was also noticed more fluctuation in recent years than in the early period. This indicates an increase in both variability and average of NDVI in the study area.

Table 1 presents the annual and seasonal trends in rainfall, maximum temperature, minimum temperature, NDVI at each station, and the whole study area during 1982-2018. The values in the table indicate the rate of change per decade estimated using SSE. The bold numbers indicate the significant change at $p<0.05$, estimated using the MMK test. The results show an increase in annual rainfall at Ishuardi and Rajshahi, but overall a decrease in rainfall for the whole study area at a rate of -2.56 $\mathrm{mm} /$ decade. The monsoon rainfall showed an increase at three out of five stations and a decrease at Dinajpur. Overall, the monsoon rainfall was also declining at a rate of $-5.74 \mathrm{~mm} /$ decade. Overall, the rainfall increased at the stations located in the southwest and no change in annual and most seasonal rainfall at other stations. The rainfall was increasing in all the seasons at Ishuardi. It was also increasing in all seasons except in pre-monsoon and winter at Rajshahi.

The annual mean of maximum temperature was increasing at three out of five stations. It increased at all stations except Rajshahi. The maximum temperature increased in monsoon and post-monsoon seasons over the whole study area at a rate of 0.245 and $0.285^{\circ} \mathrm{C} /$ decade, respectively, and decreased in winter by $0.23^{\circ} \mathrm{C} /$ decade. The changes in minimum temperature were significant at more locations compared to maximum temperature. The annual increase in minimum temperature was $0.176^{\circ} \mathrm{C} / \mathrm{decade}$. It was also increasing in all seasons except post-monsoon.

The MMK test showed a significant increase in NDVI in the study area. Annually, it was increasing at a rate of 0.014 per decade. It was also increasing for all the seasons, except winter. The highest increase was noticed during pre-monsoon by 0.039 per decade and the lowest in monsoon by 0.007 per decade. Overall, the results revealed a decrease in annual rainfall and an increase in maximum and minimum temperature and NDVI in the study area. The changes in rainfall were not significant for most of the seasons, except monsoon when it was decreasing. In contrast, the increases in temperature and NDVI were significant for most of the seasons.

Table 1. Annual and seasonal trends in rainfall, temperature and vegetation index in the study area. Values in the tables indicate the change per decade.

\section{Bold number indicates significance at $p<0.05$}

\subsection{Relationship of NDVI with annual and seasonal rainfall and temperature}

The Spearman correlation of NDVI with rainfall, maximum temperature and minimum temperature at different locations are presented using a heat map in Fig. 8. The climate variables and NDVI values were averaged for a year or season to prepare the annual and seasonal time series of climate and NDVI. Each time series consists of 37 samples (one value for each year). The time series data were then used for correlational analysis. The negative correlation coefficients are presented using red colour, the positive correlation with green colour and the near-zero correlation using yellow colour in Fig. 8. Considering a 


\begin{tabular}{|c|c|c|c|c|c|c|c|}
\hline & Season & Dinajpur & Rangpur & Ishuardi & Rajshahi & Bogra & Whole \\
\hline \multirow[t]{5}{*}{ Rainfall (mm) } & Annual & -3.59 & 1.27 & 3.18 & 0.16 & -3.67 & -2.56 \\
\hline & Pre-monsoon & 0.14 & -0.59 & 3.43 & 0.55 & 5.13 & -0.23 \\
\hline & Monsoon & -9.90 & 4.34 & 3.17 & 0.10 & -7.21 & -5.74 \\
\hline & Post-monsoon & -2.42 & 3.75 & 2.73 & 0.08 & -2.32 & -3.07 \\
\hline & Winter & -0.17 & -2.48 & 3.11 & -0.02 & -1.13 & -0.41 \\
\hline \multirow[t]{5}{*}{ Max Temp $\left({ }^{\circ} \mathrm{C}\right)$} & Annual & 0.101 & 0.328 & 0.011 & -0.289 & 0.368 & 0.030 \\
\hline & Pre-monsoon & 0.019 & 0.274 & 0.034 & 0.001 & 0.613 & -0.251 \\
\hline & Monsoon & 0.321 & 0.229 & 0.004 & -0.756 & 0.632 & 0.245 \\
\hline & Post-monsoon & 0.251 & 0.293 & 0.014 & -0.268 & 0.224 & 0.285 \\
\hline & Winter & -0.101 & 0.428 & 0.002 & 0.070 & -0.127 & -0.230 \\
\hline \multirow[t]{5}{*}{ Min Temp $\left({ }^{\circ} \mathrm{C}\right)$} & Annual & 0.015 & 0.013 & -0.474 & 0.477 & -0.121 & 0.176 \\
\hline & Pre-monsoon & 0.142 & 0.033 & 0.328 & 0.976 & 0.158 & 0.131 \\
\hline & Monsoon & 0.256 & 0.006 & -1.172 & 0.845 & 0.190 & 0.187 \\
\hline & Post-monsoon & -0.470 & 0.019 & -0.718 & 0.375 & -0.836 & 0.096 \\
\hline & Winter & 0.037 & -0.003 & 0.125 & -0.219 & -0.147 & 0.244 \\
\hline \multirow[t]{5}{*}{ NDVI } & Annual & 0.015 & -0.495 & 0.113 & 0.217 & 0.014 & 0.014 \\
\hline & Pre-monsoon & 0.040 & -0.278 & 0.027 & 0.346 & 0.032 & 0.039 \\
\hline & Monsoon & 0.010 & -0.869 & 0.365 & 0.234 & 0.007 & 0.007 \\
\hline & Post-monsoon & 0.011 & -0.249 & 0.247 & 0.216 & 0.022 & 0.016 \\
\hline & Winter & -0.001 & -0.069 & -0.275 & 0.182 & -0.003 & -0.002 \\
\hline
\end{tabular}

sample size of 37 , the Spearman correlation coefficient higher than 0.36 is significant at $p<0.05$.

Fig. 8(a) shows significant negative relation of NDVI with rainfall in monsoon at most stations. The relation was not significant in other seasons, except at one or two locations. The literature review suggests both positive and negative relationships of rainfall with NDVI. Overall, a positive correlation of NDVI with precipitation in dry climatic zones and a negative association with heavy rainfall in humid areas (Wang, 2015). Tan et al. (2015) also reporteda negative association between extreme precipitation and NDVI. Therefore, a negative relationship between rainfall and NDVI in the study area during monsoon is justifiable. A major portion (nearly $60 \%$ ) of total annual rainfall in the study area occurs during the monsoon. The heavy rainfall causes the inundation of nearly $20 \%$ of the land in the study area almost every year. The land inundation causes root rotting and defoliation of the trees (Gangashe, 2020). The 
reduction of air in plant roots causes deterioration of plant health and greenness (Basak et al., 2015). Therefore, a negative relationship between rainfall and NDVI was noticed during the monsoon in the study area. The high rainfall continues in post-monsoon months in some areas, and therefore, a significant negative correlation between rainfall and NDVI was also noticed in post-monsoon months at Rajshahi. The relationship between annual rainfall and NDVI was not significant at any locations except Borga. The high negative relation between rainfall and NDVI in monsoon has made the rainfall-NDVI relationship significant at the annual scale at Borga.

The relation between maximum temperature and NDVI was significantly positive at some stations on both annual and seasonal scales. The relationship was significant at three out of five stations during monsoon and two locations at a yearly scale. The high temperature during monsoon months helps vegetation proliferation, and therefore, a positive relation is justifiable. The NDVI-maximum temperature relationship was negative during pre-monsoon at Rajshahi station, where a significant negative NDVImaximum temperature relationship exists during pre-monsoon.

The most significant relationship between climate variables and NDVI was for minimum temperature. The NDVI in the study area was positively correlated with minimum temperature at most stations for both annual and seasonal timescales. The relationship was significant at three out of five stations during winter. This made the NDVI-minimum temperature relationship significant for the whole study area. The relationship was also significant for monsoon for the whole study area. Overall, the study revealed a negative influence of rainfall on NDVI during monsoon, and positive influence of maximum temperature in monsoon and a positive influence of minimum temperature in winter.

\subsection{Relationship of NDVI with lag rainfall and temperature}

The relationship of NDVI with rainfall and temperature for one to three months lags and the cumulative rainfall or temperature for one to three months lags was estimated to have an insight into a climate-NDVI relationship in different locations. The obtained results for rainfall at five study locations are presented in Fig. 9. A similar analysis was also conducted for maximum and minimum temperatures. The obtained results are presented using heat maps as supplementary Figs. (Fig. S1 and S2).

A significant relation was mainly noticed during the winter month of December for two-month lag rainfall or cumulative one-month lag rainfall at the northern stations. It means high rainfall in October or higher cumulative rainfall during October and November positively affect vegetation during December. Besides, NDVI showed a negative relationship with rainfall during the late monsoon months of September and October for different lags and cumulative lags. For example, Fig. 9(e) shows a significant negative relationship of July NDVI with one-month lag rainfall, August NDVI with two-month lag rainfall and September with three-month lag rainfall and so on. This indicates higher rainfall in one monsoon month negatively affect the NDVI of the next month. However, the relationship of NDVI was significant for cumulative rainfall for all lags. This indicates more rainfall in pre-monsoon months negatively affect vegetation in the early monsoon. Similarly, higher rainfall in the early monsoon negatively affects the $\mathrm{NDVI}$ in the late monsoon. 
The relationship of monthly NDVI with maximum temperature for different lags and their cumulations was not consistent at different locations and months. For example, the NDVI showed a negative correlation with maximum temperature for different lags and cumulations at Dinajpur and Bogra but positive at Rangpur and no significant relationship at Ishuardi and Rajshahi. However, a negative relationship of winter months NDVI (January and December) with maximum temperature for some lags and cumulations was noticed at most of the stations. This indicates negative impacts of post-monsoon maximum temperature on winter vegetation at some locations in the study area.

The NDVI in pre-monsoon months was positively related to the minimum temperature for different lags and cumulations at Dinajpur, Rangpur and Rajshahi. It means the higher minimum temperature in winter months helps in vegetation growth in pre-monsoon months. A positive relationship between NDVI of early monsoon months (June and July) was also noticed with minimum temperature for different lags at Ishuardi station. This indicates the higher minimum temperature in pre-monsoon months helps the proliferation of vegetation in early monsoon months at Ishuardi.

Overall, the results revealed no consistent rainfall and temperature influence on NDVI on a monthly timescale at all the locations. However, the positive impact of rainfall in post-monsoon on winter vegetation, negative impacts of the maximum temperature in pre-monsoon or early monsoon on monsoon NDVI, and the positive impacts of winter minimum temperature on pre-monsoon NDVI at some locations.

\subsection{The NDVI-climate relationships for different quantiles}

The QR analysis was conducted to have a better insight into the NDVI-climate relationship for different quantiles. The Spearman correlation assessed the association between mean NDVI and the mean of rainfall and temperature. However, it is not sufficient to assess the mean relationship only. The significant relationship for different quantiles can explain how rainfall and temperature extremes affect vegetation in the study area. The QR was conducted between NDVI and three climate variables (rainfall, maximum temperature and minimum temperature) at all the stations and the whole study area. Obtained results at Rajshahi station is shown in Fig. 10. The regression lines for different quantiles are presented in the graphs in the right column. The quantiles (0.1 to 0.9$)$ are presented using a colour ramp, where the green line represents lower quantiles, yellow indicates near to median quantiles, and the red line indicates higher quantiles. The rate of change in NDVI for the unit change in rainfall or temperature for different quantiles (0.01 to 0.99$)$ is presented using graphs in the right column. The significant changes are indicated using a red coloured line in the graph.

The results showed a decrease in NDVI with the increase in rainfall of higher quantiles while no change in NDVI for an increase in rainfall of lower quantiles (Fig. 10(a)). The changes in NDVI for the changes in different rainfall quantiles (Fig. 10(b)) revealed a positive association of NDVI for lower quantiles of rainfall and a negative association for higher quantiles. The significance of change estimated for different quantiles revealed a significant relationship for above 0.85 quantiles. It indicates the significant negative impact of extreme rainfall on vegetation at the station. The maximum temperature negatively 
correlated with NDVI for lower quantiles and positively for higher quantiles (Fig. 10(c)). However, the relation was not significant at any quantiles at Rajshahi station (Fig. 10(d)). The relationship between minimum temperature with NDVI showed decreased NDVI with increased minimum temperature for all quantiles. However, the relation was significant only for higher quantiles $(>0.90)$. Overall, the results indicated negative impacts of extreme minimum temperature on vegetation at Rajshahi.

A similar analysis was conducted for all the stations. Obtained results are presented in Supplementary Figs. S3 to S6. The results showed a significant negative relationship between extreme rainfall and NDVI, positive relationship of NDVI with extreme maximum and minimum temperature at Borga Station. The positive influence of median and higher maximum temperature quantiles and lower minimum temperature quantiles on NDVI, but no relation with rainfall for any quantiles at Ishuardi. No significant relation of NDVI with rainfall and temperature for any quantiles at Rangpur station. At Dinajpur, the extreme minimum and maximum temperature showed a positive correlation with NDVI, while near to median and higher rainfall quantities $(0.7$ to 0.85$)$ are positively correlated with NDVI.

Fig. 11 shows the relationship of NDVI with rainfall and temperature for different quantiles for the whole study area. The results revealed a negative relationship of NDVI with rainfall and a positive relationship with maximum and minimum temperatures. The relationships were significant for high quantiles (above 0.8). It indicates a significant influence of extreme climate on vegetation in the study area. Extreme rainfall significantly reduces vegetation, while extreme maximum temperature significantly increases vegetation. The increase in near median ( 0.2 to 0.5 and 0.55 to 0.6$)$ and higher $(0.65 \sim 0.94)$ quantiles of minimum temperature also increase NDVI. However, the increase is not significant for extreme high quantiles ( $>0.94$ ). The extreme rainfall causes flood and, thus, negatively affects NDVI, while higher temperature provides a favorable environment for photosynthesis, hence the proliferation of vegetation. The study also showed a greater influence of temperature compared to rainfall on NDVI in the study area. The increase in extreme rainfall by one millimeter causes a decrease in NDVI in the range of -0.015 to -0.025 . However, the $1^{\circ} \mathrm{C}$ increase in extreme maximum temperature causes an increase in NDVI in the range of 0.037 to 0.049 . The increase in minimum temperature's higher quantile $(0.85$ to 0.94$)$ by $1^{\circ} \mathrm{C}$ causes an increase in NDVI in the range of 0.028 to 0.072 . Overall, the results showed the highest impact of minimum temperature, followed by maximum temperature and rainfall on NDVI in the study area.

\section{Discussion}

The present study assessed the influences of rainfall, maximum and minimum temperature on vegetation dynamics of NWB. The relationship of NDVI with climate widely vary for different geographical regions and different scales like a month, season and year. For example, the temperature positively relates to NDVI in the cold northern region but negatively in an arid region (Pei et al., 2019). This indicates a large spatial heterogeneity of NDVI-climate nexus over the globe. Therefore, assessment of such nexus at a regional scale is very important. The present study assessed the NDVI-climate nexus in NWB, where water scarcity and environmental degradation are major concerns in recent years. 
The study revealed no consistent impact of rainfall and temperature on vegetation at all the locations. In general, the results suggest a negative influence of rainfall on NDVI during monsoon and positive effect of maximum temperature in monsoon and a positive influence of minimum temperature in winter. The lag relations between NDVI and climate factors showed higher sensitivity of NDVI to climate factors of the previous month than the current month. The relationship of NDVI with cumulative rainfall and temperature for different lags indicated more rainfall in the pre-monsoon negatively affect vegetation in the early monsoon. Higher rainfall in the early monsoon negatively affects the NDVI in the late monsoon.

The present study also assessed the influence of different quantiles of rainfall and temperature on NDVI to understand the impacts of climatic extremes on vegetation in the study area. The results indicated that extreme rainfall significantly reduces vegetation, while extreme maximum temperature significantly increases vegetation. The increase in higher quantiles of minimum temperature also increases NDVI, but the increases are not significant for extreme high quantiles. This again justifies the findings using correlational analysis. The comparative analysis of the influences of different variables on NDVI indicates the highest impact of minimum temperature, followed by maximum temperature and rainfall on NDVI in the study area.

The negative impact of rainfall on vegetation in the humid region is consistent with the finding of previous studies (Wang, 2015; Tan et al., 2015; Basak et al., 2015; Gangashe, 2020). The tree defoliation due to high rainfall-induced land inundation and consequent reduction in greenness is the cause of the negative relation of NDVI with monsoon rainfall of NWB (Gangashe, 2020). Maselli et al. (2004) and Leilei et al. (2014) reported the positive impact of temperature on vegetation in the winter months. Pan et al. (2019) also showed a positive relation of NDVI with temperature in high rainfall areas. This is consistent with the positive relation of NDVI with temperature in monsoon months found in this study. Generally, the photosynthesis process increases with the temperature increase until it reaches a threshold (Markings, 2018). Therefore, the higher temperature during winter and monsoon months was positively related to NDVI in the study area.

The present study revealed a significant increase in NDVI in the study area at a rate of 0.014 per decade. It was also increasing in all the seasons, except winter. The highest increase was noticed during premonsoon by 0.039 per decade and the lowest in monsoon by 0.007 per decade. The trend analysis also revealed a significant increase in temperature and decreased rainfall in the study area.

Previous studies (Shahid et al., 2010) also revealed an increase in temperature in Bangladesh at a rate of $0.091^{\circ} \mathrm{C}$ per decade. However, Shahid et al. (2010) showed an increase in rainfall in Bangladesh by nearly $5.53 \mathrm{~mm} /$ year. This study showed a decrease in rainfall in northern Bangladesh. The highest decrease was in monsoon rainfall by $-5.74 \mathrm{~mm} /$ year. The difference in finding the present study with Shahid (2010) may be due to different data periods used for trend analysis. The decrease in monsoon rainfall and increase in temperature winter minimum temperature and summer maximum temperature caused a large increase in NDVI in those seasons in Bangladesh. 
The projection of climate in the study area showed a moderate or insignificant increase in rainfall in the study area for different future scenarios. The highest increase in rainfall was projected for the low rainfall winter season by two to three folds. The highest increase in monsoon rainfall was projected in the range of $4.3 \%$ at Rajshahi to nearly $21.1 \%$ at Rangpur for radiative concentration pathways scenarios. A relative high increase in post-monsoon rainfall also projected by different global climate models. The projected maximum increase in post-monsoon rainfall was in the range of 3.2 to $42.8 \%$. The changes in premonsoon rainfall were in the range of -1.5 to $9.8 \%$. The rainfall in post-monsoon months positively relates to NDVI in the winter months (January and December), while monsoon rainfall negatively affects NDVI in the study area. The increase in rainfall in post-monsoon and winter would increase vegetation. However, the increase in monsoon rainfall is not significant, and therefore, the negative impact of high monsoon rainfall on vegetation would not be high in the future.

The temperature in the study area showed a significant rise in recent decades. The minimum temperature was increasing more compared to the maximum temperature. The projection of climate for different scenarios revealed a continuation of the present trend in temperature rise in the study area. The projected increase in maximum temperature was between 1.0 and $1.1^{\circ} \mathrm{C}$ for the mildest scenarios (RCP2.6) and 5.4 to $6.0^{\circ} \mathrm{C}$ for the business-as-usual scenarios (RCP8.5). Similarly, the projected increase in minimum temperature was in the range of 0.9 to $1.7^{\circ} \mathrm{C}$ for RCP2.6 and 4.3 to $8.8^{\circ} \mathrm{C}$ for RCP8.5. The present study showed a higher positive impact of maximum and minimum temperature on vegetation in the study area. Therefore, future temperature changes would cause an increase in vegetation cover in the study area. The highest impact on vegetation was for minimum temperature. The temperature projection showed a higher increase in minimum temperature than the maximum temperature. Therefore, as noticed in the historical $\mathrm{NDVI}$, the high rate of increase is supposed to continue for the future. Overall, the projection of climate indicates a large positive impact of climate change on vegetation in the study area.

Some parts of NWB is the least vegetated area of the country. Sparse vegetation makes the area like a semiarid region during the dry season. The region experiences higher temperature extremes compared to other parts of the country. It also receives relative less rainfall. Variability of rainfall in the area is also high, and thus, it is more susceptible to droughts. The regions experience several major droughts in the last few decades. The initiation of groundwater-based irrigated agriculture in the late eighties has improved the environment and vegetation in the region. A favorable climate has accelerated that growth and caused a large increase in NDVI in the study area.

The NDVI is a measure of vegetation phenology and primary productivity. The increase in NDVI means increasing primary productivity (Benayas and Scheiner 2002, Levin et al. 2007). The increase in primary productivity also indicates a regional variation in species richness in NWB (Gould 2000). Vegetation has a direct impact on the micro-climate of an area (Pour et al., 2020). Vegetation enhances air moisture of the surroundings, absorbs the sun's radiation, cools the surrounding environment and significantly improves the microclimate of an area (David, 2009). Increased moisture creates a favorable environment for the flora and fauna of that region. Recent studies on vegetation impacts on dryness and dust storms indicate positive effects on vegetation reduction of dryness and increase in environmental sustainability (Lee et 
al. 2009; Kimura, 2012). The increasing trend in vegetation and its possible continuation due to a favorable climate projection might improve the bio environment and environmental sustainability.

\section{Conclusions}

This study presents the results of vegetation's relationship with climate in NWB. The NWB is the most water-stress region, thus less vegetated compared to other parts of the country. The climate of the study area is changing like other parts of the globe. Therefore, it was vital to investigate the impacts of climate and its changes on vegetation to anticipate the possible future vegetation and ecological condition in the study area. The study revealed a negative effect of rainfall and positive impacts on temperature on vegetation in the study area. However, the effects of the climate variables were significant only for extreme high quantiles. This indicates negative implications of extreme rainfall and positive implication of temperature on vegetations. An insignificant increase in rainfall while a large temperature rise, projected for the study area, would provide a favorable environment for the proliferation of vegetation. It indicates an increasing trend in historical NDVI would follow in the future. Here, few points should be noted. The climate alone cannot explain all the changes in vegetation, which means the influence of other human factors for the changes in NDVI. In the future, various anthropogenic factors can be considered along with climate for a better understanding of vegetation changes in Bangladesh.

\section{Declarations}

\section{Acknowledgment}

The authors are grateful to Bangladesh Meteorological Department (BMD) for providing data on temperature and rainfall. The authors are also grateful to United States Geological Survey (USGS) for providing data on vegetation covers through their website. The Normalized Difference Vegetation Index (NDVI) data were derived from the Terra Moderate Resolution Imaging Spectroradiometer (MODIS) Vegetation Indices (MOD13Q1) Version 6, which was collected for the years 1982-2018. The data is freely available from (https://lpdaacsvc.cr.usgs.gov/appeears/).

\section{Funding}

Not Applicable

\section{Conflict of interest}

The authors declare no conflict of interest.

\section{Availability of data:}

All data used in the study are available in the public domain. Those are also available for sharing on request to the corresponding author. 


\section{Availability of code}

The codes used for the processing of data can be provided on request to the corresponding author.

\section{Authors contribution}

All the authors contributed to conceptualize and design the study. Concept was developed by Mohammad Ahsan Uddin; the modelling was done by Maksud Kamal and ShamsuddinShahid; an initial draft of the paper was prepared by Maksud Kamal and Mohammad Ahsan Uddin. The article was repeatedly revised to generate the final version by Maksud Kamal and Shamsuddin Shahid.

\section{Consent for publication}

All the authors consented to publish the paper

\section{Ethics approval}

Not Applicable

\section{Consent to participate}

Not Applicable

\section{References}

Alhumaima, A.S.\& Abdullaev, S.M. (2020). Tigris Basin Landscapes: Sensitivity of Vegetation Index NDVI to Climate Variability Derived from Observational and Reanalysis Data. Earth Interactions. 24. 1-18. 10.1175/EI-D-20-0002.1.

Almeida-Ñauñay, A. F., Benito, R. M., Quemada, M., Losada, J. C., \& Tarquis, A. M. (2021). The VegetationClimate System Complexity through Recurrence Analysis. Entropy, 23(5), 559.

Basak, S. R., Basak, A. C., \& Rahman, M. A. (2015). Impacts of floods on forest strees and their coping strategies in Bangladesh. Weather and Climate Extremes, 7, 43-48.

Benayas J.M.R. \& Scheiner S.M. (2002). Plant diversity, biogeography and environment in Iberia: Patterns and possible causal factors. Journal of Vegetation Science13: 245-258

Bi, J.; Xu, L.; Samanta, A.; Zhu, Z.C.; Myneni, R. (2013) Divergent Arctic-Boreal Vegetation Changes between North America and Eurasia over the Past 30 Years. Remote Sens. 5, 2093-2112.

Buditama, G., Saiya, H. G., \& Putri, N. P. (2021, March). Effects of climate change on dry land agriculture vegetation index in Nangapanda, East Nusa Tenggara. In IOP Conference Series: Earth and Environmental Science (Vol. 716, No. 1, p. 012013). IOP Publishing. 
Cao, D., Zhang, J., Xun, L., Yang, S., Wang, J., \& Yao, F. (2021). Spatiotemporal variations of global terrestrial vegetation climate potential productivity under climate change. Science of The Total Environment, 770, 145320.

Chen, A., Huang, L., Liu, Q., \& Piao, S. (2021). Optimal temperature of vegetation productivity and its linkage with climate and elevation on the Tibetan Plateau. Global Change Biology, 27(9), 1942-1951.

Cheng F.Z., Han, X., Tang, S. et al.(2021).An Improved Model for Evaluating Ecosystem Service Values Using Land Use/Cover and Vegetation Parameters. J Meteorol Res35, 148-156.

https://doi.org/10.1007/s13351-021-9199-x

David, N.M (2009): Landscape Design. First Edition 2009. Archimedia Publishing, Ltd, Enugu Nigeria, Arochukwu Ave Independence Layout. P.O. Box 329, Enugu. ISBN 978-073-605.

Gangashe AT (2020) Assessing the impacts of flooding on vegetation cover in the Shashe Limpopo confluence area using earth observation data. Masters Thesis, University of the Witwatersrand, Johannesburg, South Africa

Ge, W., Deng, L., Wang, F., \& Han, J. (2021). Quantifying the contributions of human activities and climate change to vegetation net primary productivity dynamics in China from 2001 to 2016. Science of The Total Environment, 773, 145648.

Gould W.A. (2000). Remote sensing of vegetation, plant species richness, and regional diversity hotspots. Ecological Applications10: 1861-1870.

Hagfors, L., Paraschiv, F., Molnar, P., Westgaard, S. (2016a). Using quantile regression to analyze the effect of renewables on eex price formation. Renewable Energy and Envi- ronmental Sustainability 1 (32).

Hou, W.J.; Gao, J.B.; Wu, S.H.; Dai, E.F.(2015). Interannual Variations in Growing-Season NDVI and Its Correlation with Climate Variables in the Southwestern Karst Region of China. Remote Sens. 7, 1110511124.

Jiang, L.L.; Jiapaer, G.; Bao, A.M.; Guo, H.; Ndayisaba, F.(2017). Vegetation dynamics and responses to climate change and human activities in Central Asia. Sci. Total Environ.599, 967-980.

Kendall, M.G. (1948). Rank Correlation Methods; Griffin: Oxford, UK.

Khan, N., Shahid, S., Juneng, L., Ahmed, K., Ismail, T., \& Nawaz, N. (2019). Prediction of heat waves in Pakistan using quantile regression forests. Atmospheric Research, 221, 1-11.

Khwarahm, N. R., Ararat, K., Qader, S., \& Sabir, D. K. (2021). Modeling the distribution of the Near Eastern fire salamander (Salamandra infraimmaculata) and Kurdistan newt (Neurergus derjugini) under current and future climate conditions in Iraq. Ecological Informatics, 63, 101309. 
Kim, S. W., Chun, K. W., Kim, M., Catani, F., Choi, B., \&Seo, J. I. (2021). Effect of antecedent rainfall conditions and their variations on shallow landslide-triggering rainfall thresholds in South Korea. Landslides, 18(2), 569-582.

Kimura, R. (2012). Factors contributing to dust storms in source regions producing the yellow-sand phenomena observed in Japan from 1993 to 2002.J. Arid Environ.80, 40-44.

Koenker R (2005) Quantile regression (no. 38). Cambridge university press.

Koenker R, Bassett G (1978) Regression quantiles. Econometrica 46(1):33.

https://doi.org/10.2307/1913643

Koenker, R. (2015). Quantreg: QuantileRegression.URLhttps://CRAN.R-project.org/package=quantreg. R package version 5.19

Kuan, Y.S., Gamse, J.T., Schreiber, A.M., and Halpern, M.E. (2007) Selective asymmetry in a conserved forebrain to midbrain projection. Journal of experimental zoology. Part B, Molecular and developmental evolution. 308(5):669-678.

Lamchin, Munkhnasan\& Wang, Wangyel \& Lim, Chul-Hee \& Ochir, Altansukh\&Ukrainski, Pavel\&Gebru, Belay \& Choi, Yuyoung\& Woo, Seong\& Lee, Woo-Kyun. (2020). Understanding global spatio-temporal trends and the relationship between vegetation greenness and climate factors by land cover during 19822014. Global Ecology and Conservation.

Lee, E. H. \&Sohn, B. J.(2009). Examining the impact of wind and surface vegetation on the Asian dust occurrence over three classified source regions. J.Geophys. Res.114, D06205.

Leilei, L., Jianrong, F., \& Yang, C. (2014, March). The relationship analysis of vegetation cover, rainfall and land surface temperature based on remote sensing in Tibet, China. In IOP conference series: earth and environmental science (Vol. 17, No. 1, p. 012034). IOP Publishing.

Levin N., Shmida A., Levanoni O., Tamari H. \& Kark S. (2007). Predicting mountain plant richness and rarity from space using satellite-derived vegetation indices. Diversity \& Distributions13: 692-703.

Li, J., Su, Z., Jiang, J., Chen, W., Yu, N., Li, X., ...\& Wei, J. (2021, March). Spatial-Temporal Change in Vegetation Cover and Climate Factor Drivers of Variation in the Haihe River Basin 2003-2016. In IOP Conference Series: Earth and Environmental Science (Vol. 697, No. 1, p. 012005). IOP Publishing.

Li, Z.; Qi, F.; Shang, G.; Sun, L.; Xia, Y.(2018). Spatial-temporal change of vegetation cover and its relationship with SPEI in Hutuo river basin. South-to-North Water Transf. Water Sci. Technol. 16, 135-143.

Liu, S.; Tian, Y.; Yin, Y.; An, N.; Dong, S.(2015) Effects of climate change on normalized difference vegetation index based on the multiple analysis of standardized precipitation evapotranspiration index methods in the Lancang River basin. Clima. Environ. Res. 20, 705-714. [CrossRef] 
Liu, X.F.; Zhu, X.F.; Li, S.S.; Liu, Y.X.; Pan, Y.Z.(2015). Changes in Growing Season Vegetation and Their Associated Driving Forces in China during 2001-2012. Remote Sens.7, 15517-15535.

Liu, Y.B.; Xiao, J.F.; Ju, W.M.; Xu, K.; Zhou, Y.L.; Zhao, Y.T.(2016) Recent trends in vegetation greenness in China significantly altered annual evapotranspiration and water yield. Environ. Res. Lett.11, 14.

Luo, M., Xie, L., Chakraborty, S. et al.(2021). A five-transgene cassette confers broad-spectrum resistance to a fungal rust pathogen in wheat. Nat Biotechno/39, 561-566. https://doi.org/10.1038/s41587-02000770-x

Madonsela S, Cho M.A, Ramoelo A, Mutanga O, Naidoo L. (2018). Estimating tree species diversity in the savannah using NDVI and woody canopy cover. Int J Appl Earth ObservGeoinform. 66:106-115.

Mann, H.B. (1945). Nonparametric tests against trend. Econometrica. 13, 245-259.

Markings, S. (2018). The Effect of Temperature on the Rate of Photosynthesis.

https://sciencing.com/effect-temperature-rate-photosynthesis-19595.html

Maselli, F.(2004). Monitoring forest conditions in a protected Mediterranean coastal area by the analysis of multiyear NDVI data. Remote Sens. Environ. 89, 423-433.

Measho, S., Chen, B., Pellikka, P., Guo, L., Zhang, H., Cai, D., ...\&Ge, M. (2021). Assessment of Vegetation Dynamics and Ecosystem Resilience in the Context of Climate Change and Drought in the Horn of Africa. Remote Sensing, 13(9), 1668.

Mishra, S. N., Gupta, H. S., \& Kulkarni, N. (2021). Impact of climate change on the distribution of Sal species. Ecological Informatics, 61, 101244.

Mkhabela, M.S. \& Bullock, Paul \& Raj, Shammi\& Wang, Shusen\& Yang, Y.. (2011). Crop yield forecasting on the Canadian Prairies using MODIS NDVI data. Agricultural and Forest Meteorology - AGR FOREST METEOROL. 151. 385-393. 10.1016/j.agrformet.2010.11.012.

Mohsenipour, M., Shahid, S., Ziarh, G. F., \&Yaseen, Z. M. (2020). Changes in monsoon rainfall distribution of Bangladesh using quantile regression model. Theoretical and Applied Climatology, 142(3), 1329-1342.

Nashwan, M.S.; Shahid, S.; Abd Rahim, N.(2019). Unidirectional trends in annual and seasonal climate and extremes in Egypt. Theor. Appl. Climatology. 136, 457-473.

Pan, S., Zhao, X., \&Yue, Y. (2019). Spatiotemporal changes of NDVI and correlation with meteorological factors in northern china from 1985-2015. In E3S Web of Conferences (Vol. 131, p. 01040). EDP Sciences.

Parmesan, C.(2006). Ecological and evolutionary responses to recent climate change. Annu. Rev. Ecol. Evol. Syst.37, 637-669. 
Pei, Z., Fang, S., Yang, W., Wang, L., Wu, M., Zhang, Q., ...\&Khoi, D. N. (2019). The relationship between NDVI and climate factors at different monthly time scales: a case study of grasslands in inner Mongolia, China (1982-2015). Sustainability, 11(24), 7243.

Pour, S. H.; Shahid, S.; Chung, E.-S.; Wang, X.-J.(2018). Model output statistics downscaling using support vector machine for the projection of spatial and temporal changes in rainfall of Bangladesh. Atmospheric research,213, 149-162.

Pour, S.H.;Wahab, A.K.A.;Shahid, S.; Asaduzzaman, M.; Dewan, A. (2020). Low impact development techniques to mitigate the impacts of climate-change-induced urban floods: current trends, issues and challenges. Sustain. Cities and Society, 62, Article 102373.

Pumo, D., \&Noto, L. V. (2021). Exploring the linkage between dew point temperature and precipitation extremes: A multi-time-scale analysis on a semiarid Mediterranean region. Atmospheric Research, 254, 105508.

Qi, X.Z.; Jia, J.H.; Liu, H.Y.; Lin, Z.S. (2019). Relative importance of climate change and human activities for vegetation changes on China's silk road economic belt over multiple timescales. Catena, 180, 224237.

Sa'adi, Z., Shahid, S., Ismail, T., Chung, E. S., \& Wang, X. J. (2017). Distributional changes in rainfall and river flow in Sarawak, Malaysia. Asia-Pacific Journal of Atmospheric Sciences, 53(4), 489-500.

Sen, P.K.(1968) Estimates of the regression coefficient based on Kendall's tau. Journal of the American Statistical Association, 63, 1379-1389.

Shahid, S. (2008). Spatial and temporal characteristics of droughts in the western part of Bangladesh. Hydrological Processes: An International Journal, 22(13), 2235-2247.

Shahid, S. (2011). Impact of climate change on irrigation water demand of dry season Boro rice in northwest Bangladesh. Climatic change, 105(3), 433-453.

Shahid, S., \&Hazarika, M. K. (2010). Groundwater drought in the northwestern districts of Bangladesh. Water resources management, 24(10), 1989-2006.

Sun H., Wang J., Xiong J., Bian J., Jin h., Cheng W., \& Li A.(2021). "Vegetation Change and Its Response to Climate Change in Yunnan Province, China", Advances in Meteorology, vol. 2021, Article ID 8857589, 20 pages, 2021. https://doi.org/10.1155/2021/8857589

Tan, J., C. Jakob, W.B. Rossow, and G. Tselioudis. (2015). Increases in tropical rainfall driven by changes in frequency of organized deep convection. Nature, 519, 451-454, doi:10.1038/nature14339.

Treppiedi, D., Cipolla, G., Francipane, A., \&Noto, L. V. (2021). Detecting precipitation trend using a multiscale approach based on quantile regression over a Mediterranean area. International Journal of 
Climatology.

Van Le, H., Hoang, D. A., Tran, C. T., Nguyen, P. Q., Hoang, N. D., Amiri, M., ... \& Bui, D. T. (2021). A new approach of deep neural computing for spatial prediction of wildfire danger at tropical climate areas. Ecological Informatics, 63, 101300.

Walther, G.R.; Post, E.; Convey, P.; Menzel, A.; Parmesan, C.; Beebee, T.J.C.; Fromentin, J.M.;HoeghGuldberg, O.; Bairlein, F.(2002). Ecological responses to recent climate change. Nature, 416, 389-395.

Wang, J., Wang, K., Zhang, M., Zhang, C.(2015). Impacts of climate change and human activities on vegetation cover in hilly southern China. Ecological Engineering, vol 81, 451-461.

Wang, S., Liu, Q., \& Huang, C. (2021). Vegetation Change and Its Response to Climate Extremes in the Arid Region of Northwest China. Remote Sensing, 13(7), 1230.

Yan, M., Xue, M., Zhang, L., Tian, X., Chen, B., \& Dong, Y. (2021). A Decade's Change in Vegetation Productivity and Its Response to Climate Change over Northeast China. Plants, 10(5), 821.

Yoshida, T. (2021). Extreme value inference for quantile regression with varying coefficients. Communications in Statistics-Theory and Methods, 50(3), 685-710.

You MJ, Castrillon DH, Bastian BC, O'Hagan RC, Bosenberg MW, Parsons R et al. (2002). Genetic analysis of Pten and Ink4a/Arf interactions in the suppression of tumorigenesis in mice. ProcNat/AcadSci USA99: $1455-1460$.

Zahoor, B., Liu, X., Kumar, L., Dai, Y., Tripathy, B. R., \& Songer, M. (2021). Projected shifts in the distribution range of Asiatic black bear (Ursus thibetanus) in the Hindu Kush Himalaya due to climate change. Ecological Informatics, 63, 101312.

Zarei, Azin \& Asadi, Esmaeil \& Ebrahimi, Ataollah \& Jafari, Mohammad \& Malekian, Arash \& Mohammadi, Hamid \& Chemura, Abel \& Maskell, Gina. (2020). Prediction of future grassland vegetation cover fluctuation under climate change scenarios. Ecological Indicators. 119. 10.1016/j.ecolind.2020.106858.

Zhang, R., Wang, P., Mao, G., Chen, A., \& Liu, J. (2021). Spatiotemporal variation of enhanced vegetation index in the Amazon Basin and its response to climate change. Physics and Chemistry of the Earth, Parts A/B/C, 103024.

Zhao, Lin \& Dai, Aiguo \& Dong, Bo. (2018). Changes in global vegetation activity and its driving factors during 1982-2013. Agricultural and Forest Meteorology, 249. 198-209. 10.1016/j.agrformet.2017.11.013.

Zhao, W., Yu, X., Jiao, C., Xu, C., Liu, Y., \& Wu, G. (2021). Increased association between climate change and vegetation index variation promotes the coupling of dominant factors and vegetation growth. Science of the Total Environment, 767, 144669. 
Zhu, W.; Mao, F.; Xu, Y.; Zheng, J.; Song, L. (2019). Analysis on Response of Vegetation Index to Climate Change and Its Prediction in the Three-Rivers-Source Region. Plateau Meteorol.,38, 693-704.

Figures

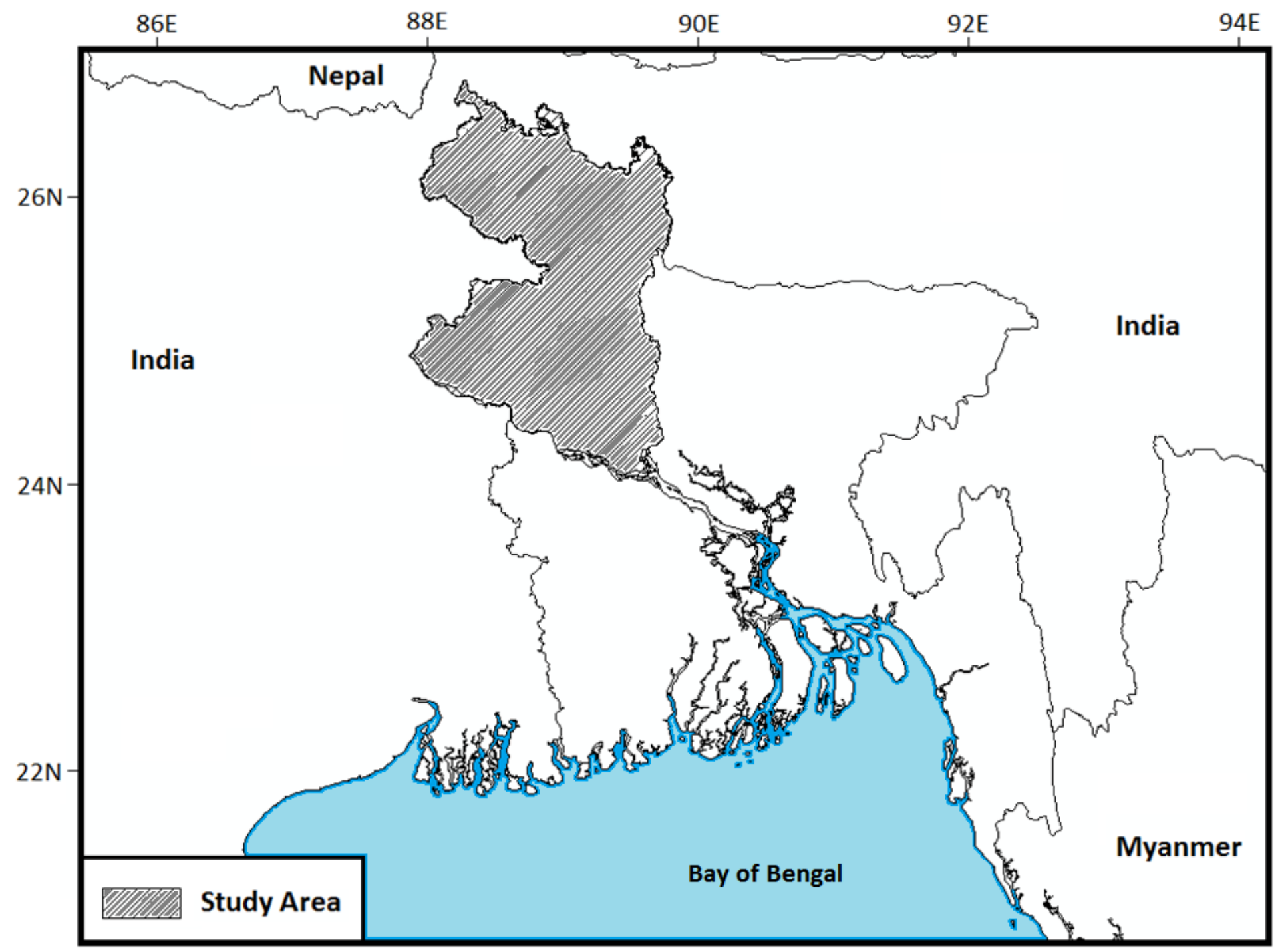

Figure 1

The geographical position of the study area in Bangladesh 


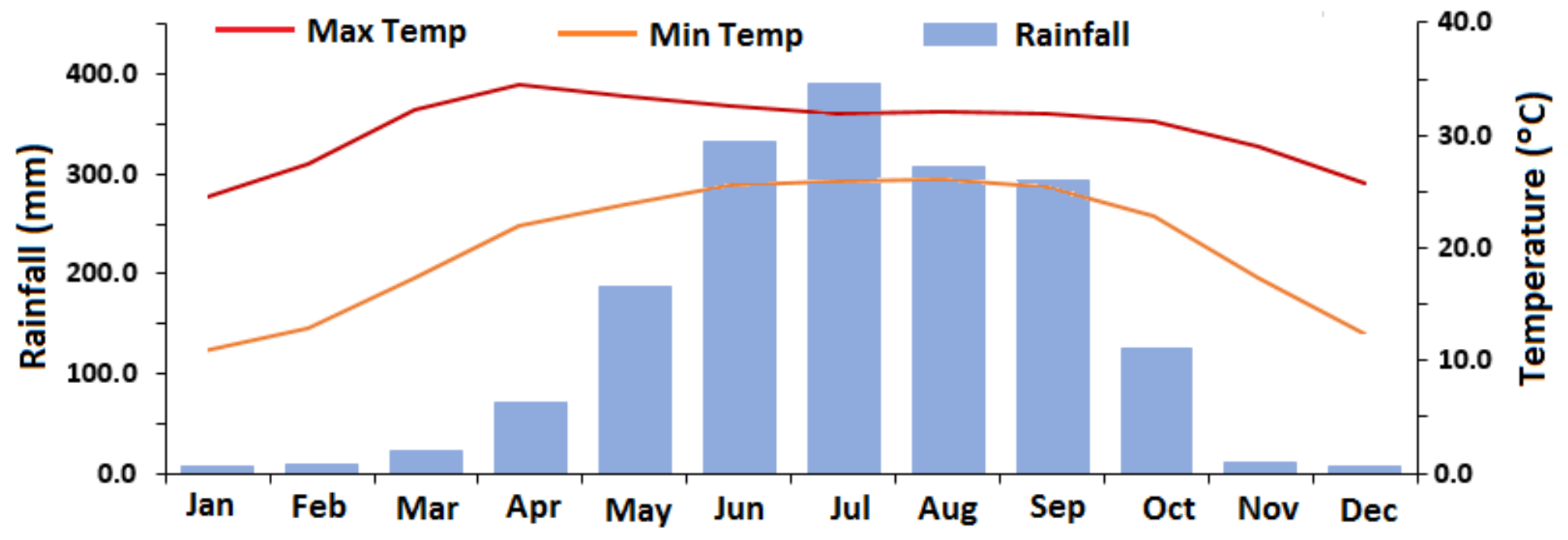

Figure 2

Seasonal variability of rainfall and temperature in Northwest Bangladesh
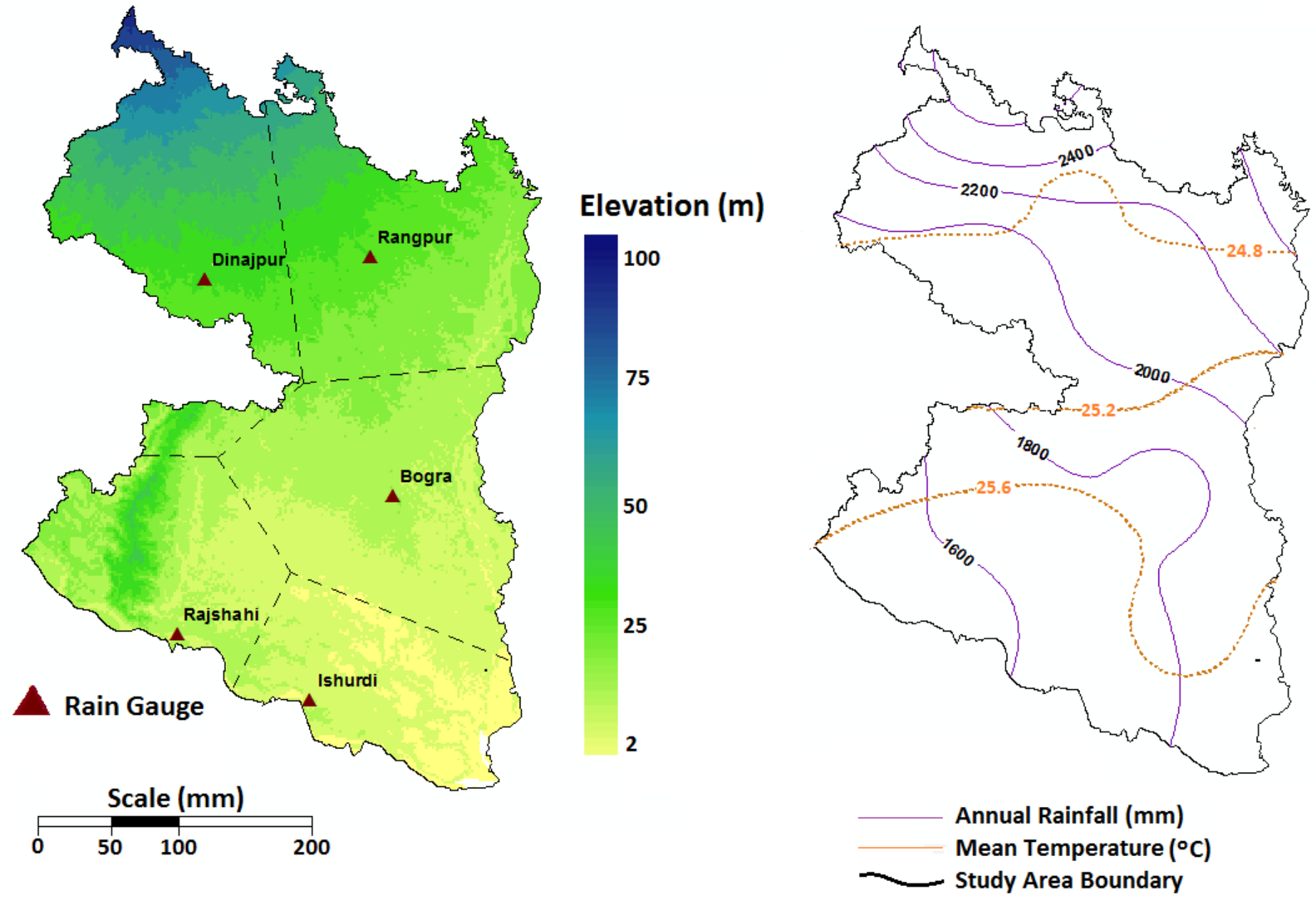

(a)

(b)

Figure 3 
(a) Topography and location of rain gauges; (b) geographical variability of annual rainfall and mean temperature in Northwest Bangladesh

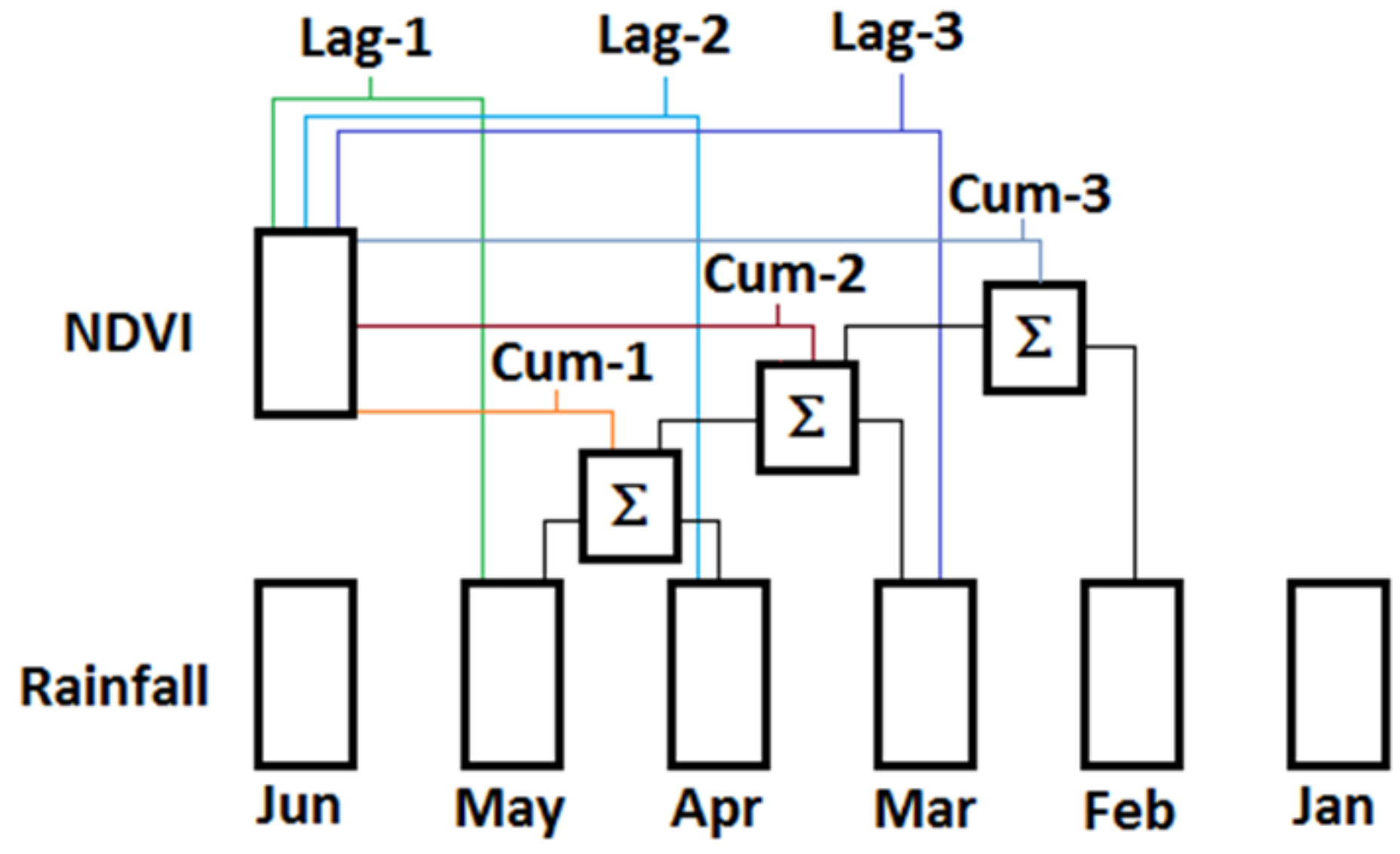

Figure 4

Estimation of the relationship of NDVI with rainfall and temperature for different lags and cumulative rainfall and temperature for different lags. 

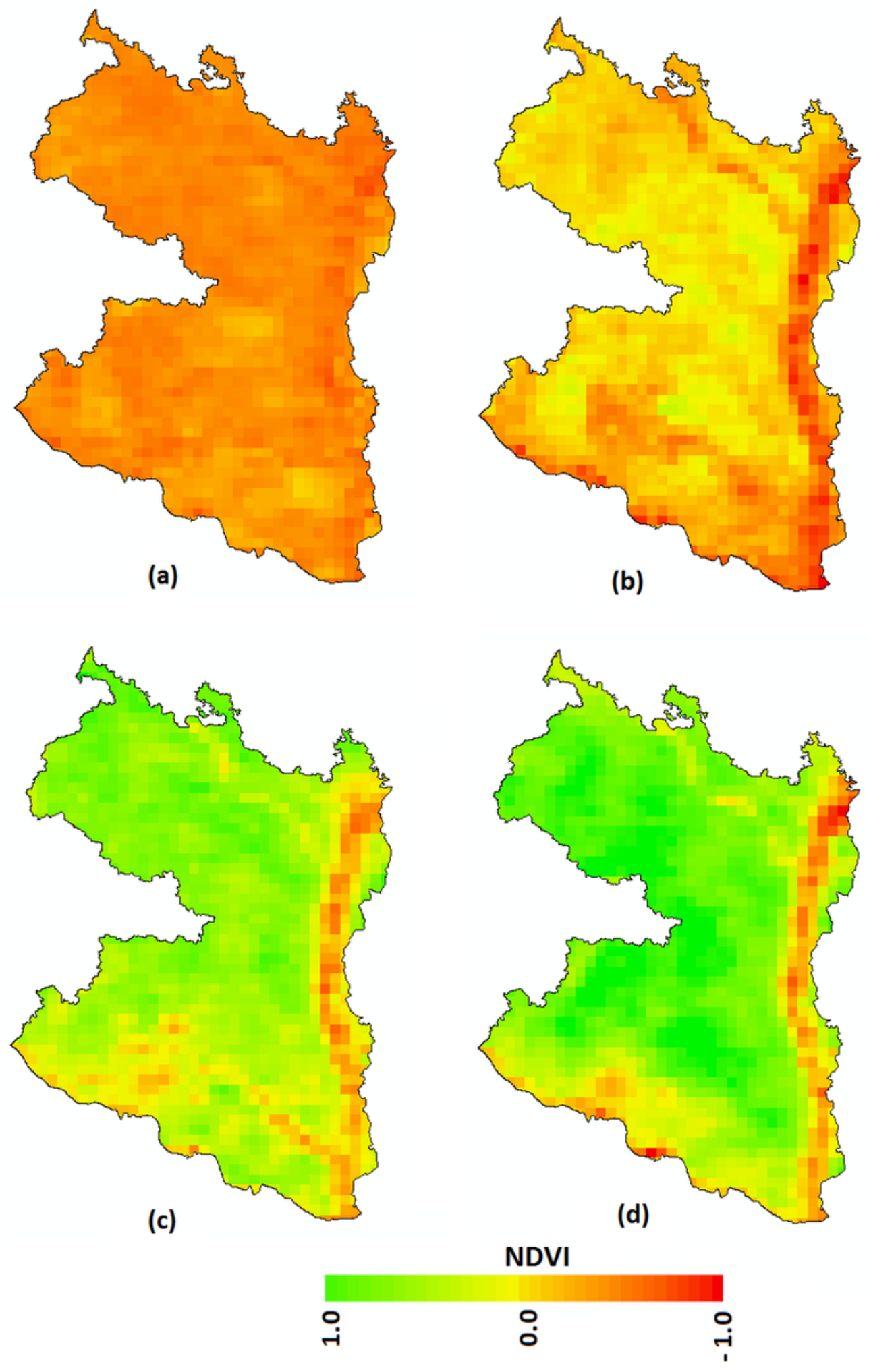

Figure 5

Spatial distribution of mean NDVI during (a) winter; (b) pre-monsoon; (c) monsoon; and (d) post-monsoon seasons in the study area for the period $1982 \llbracket 2018$ 

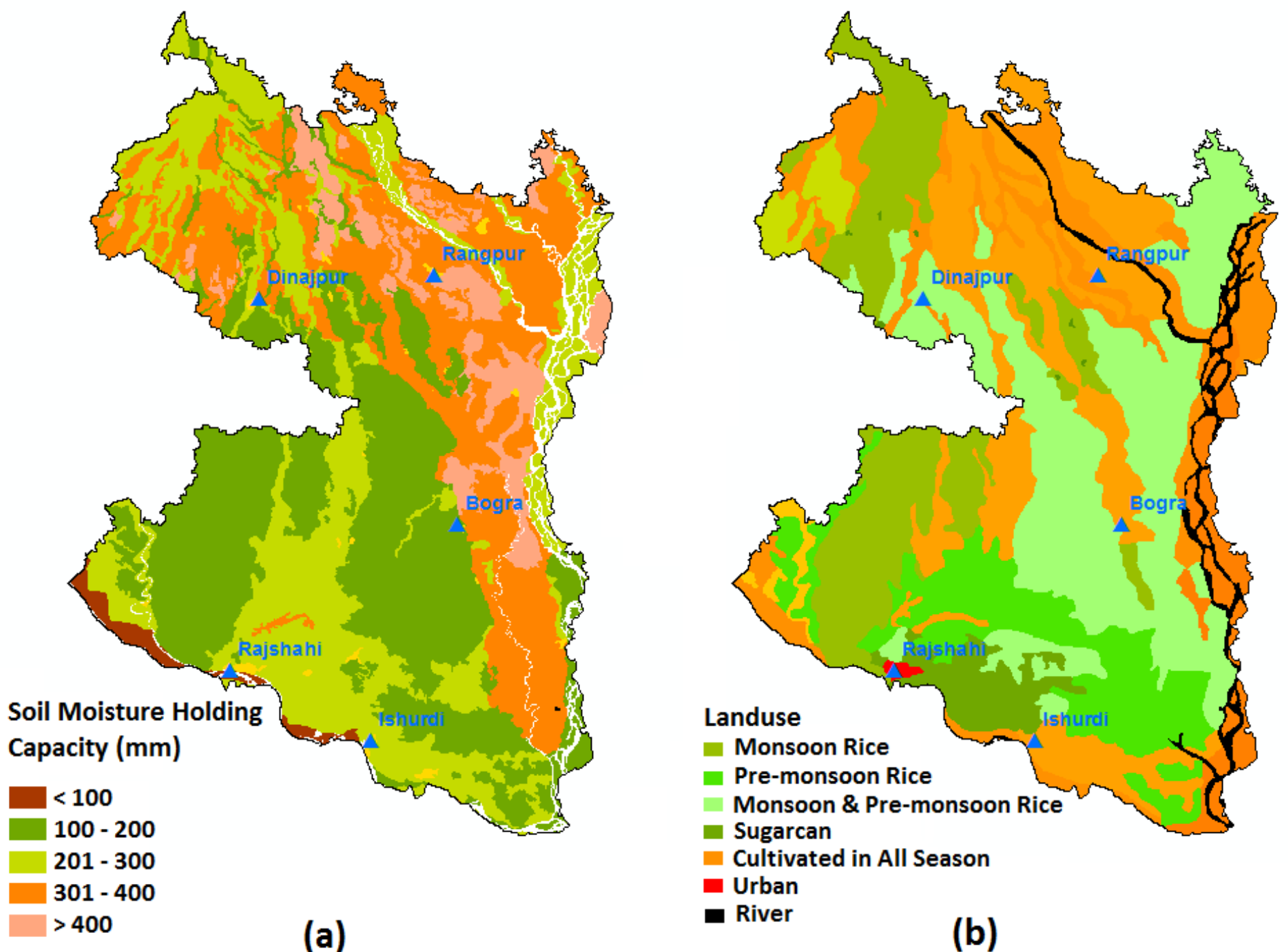

Figure 6

Maps of (a) soil moisture-holding capacity; (b) landuse of northwest Bangladesh 


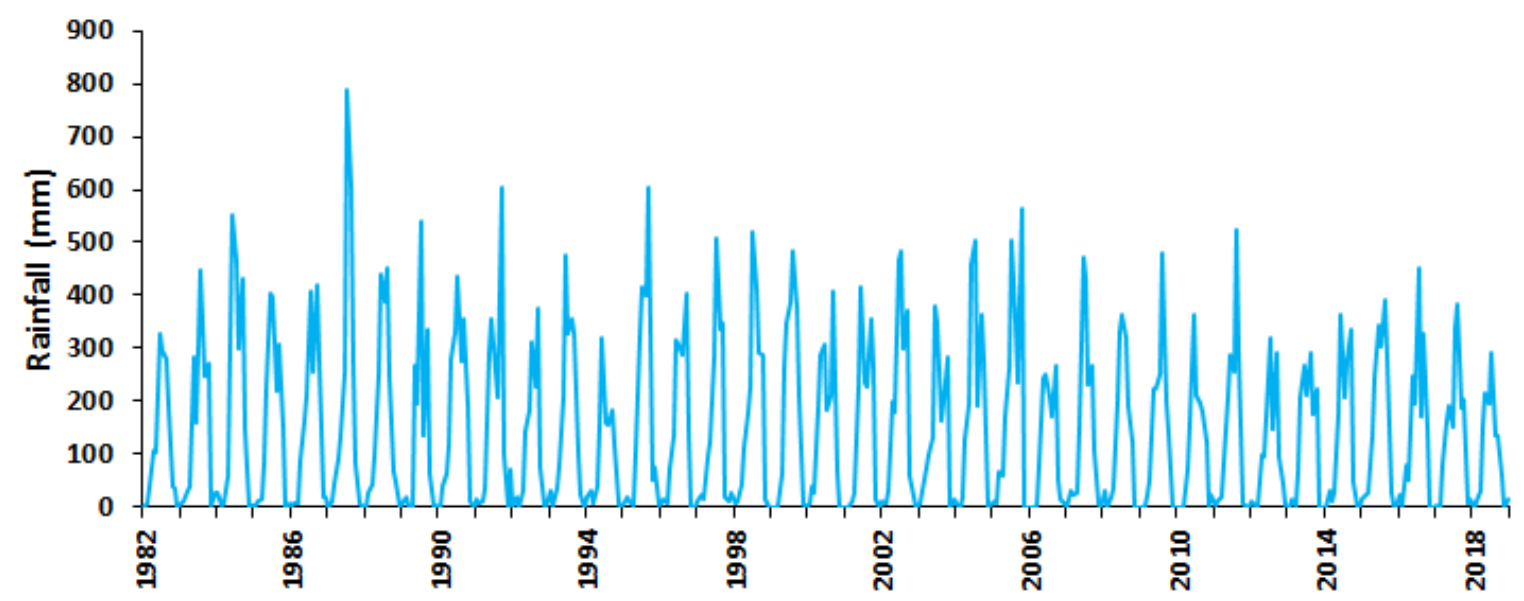

(a)

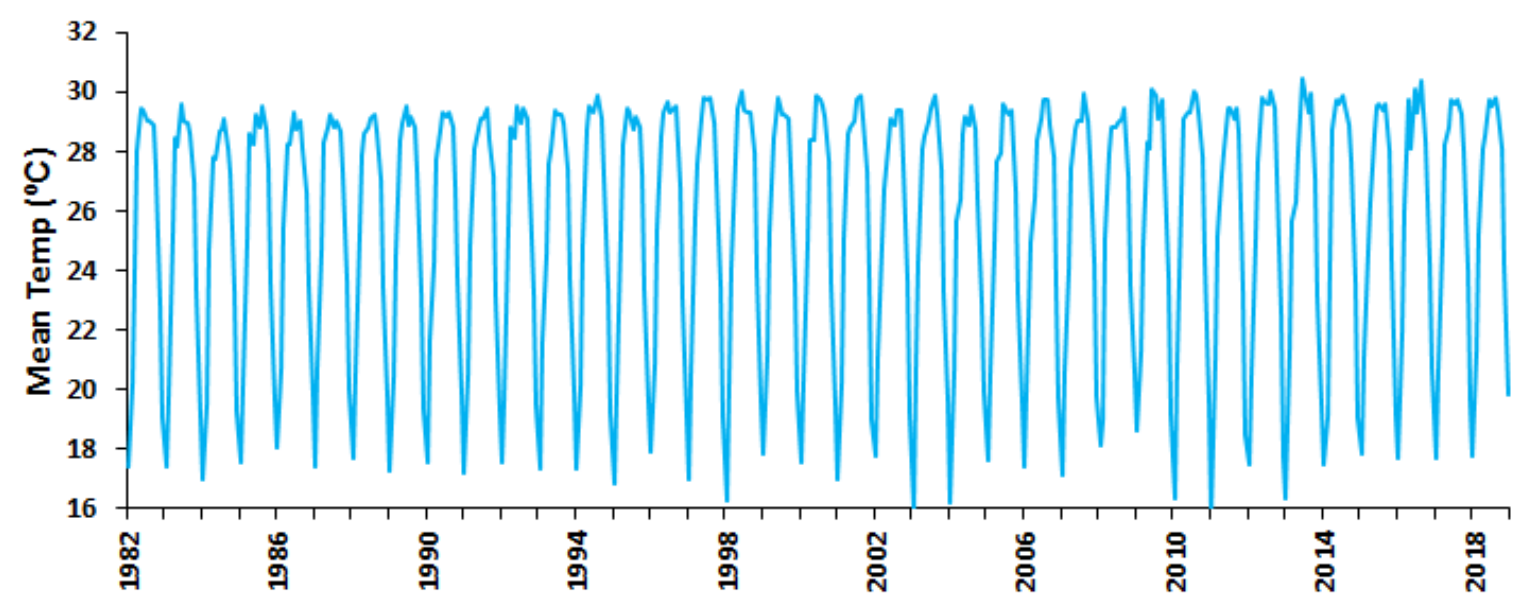

(b)

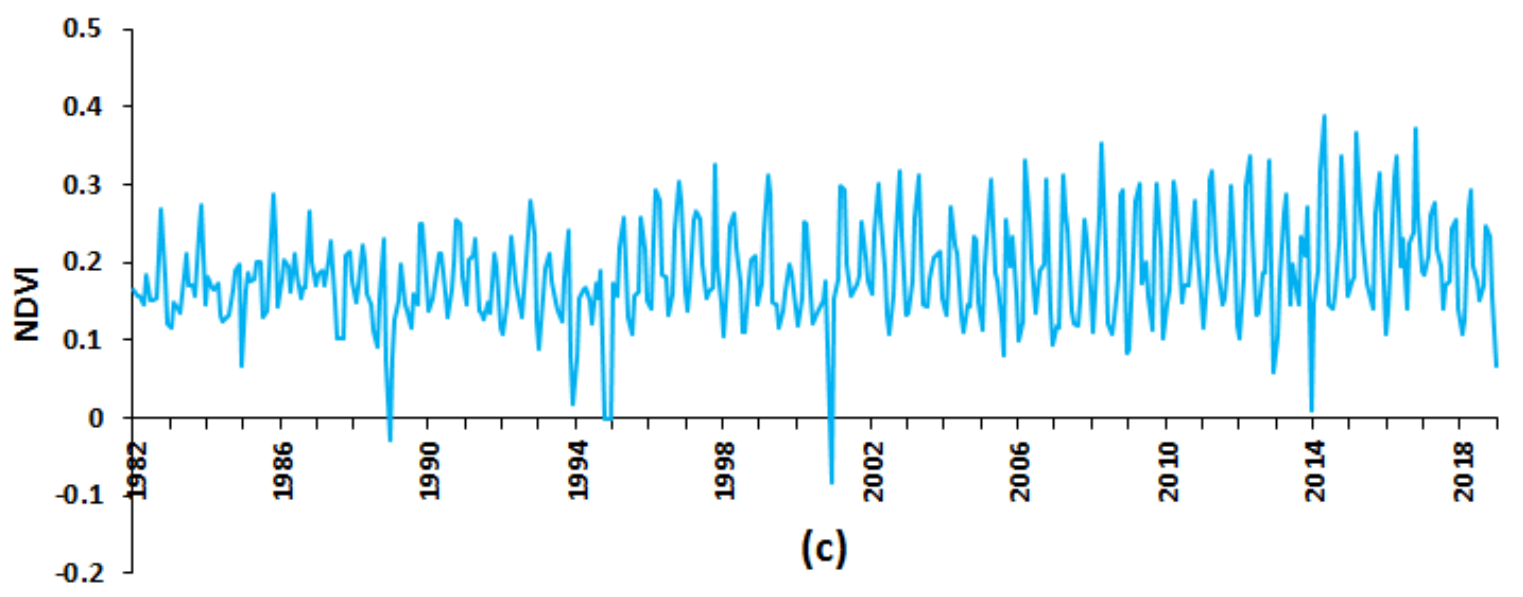

Figure 7

Temporal changes in areal average of monthly (a) total rainfall; (b) daily mean temperature; and (c) mean NDVI in northwest Bangladesh for the period 1982ख2018 


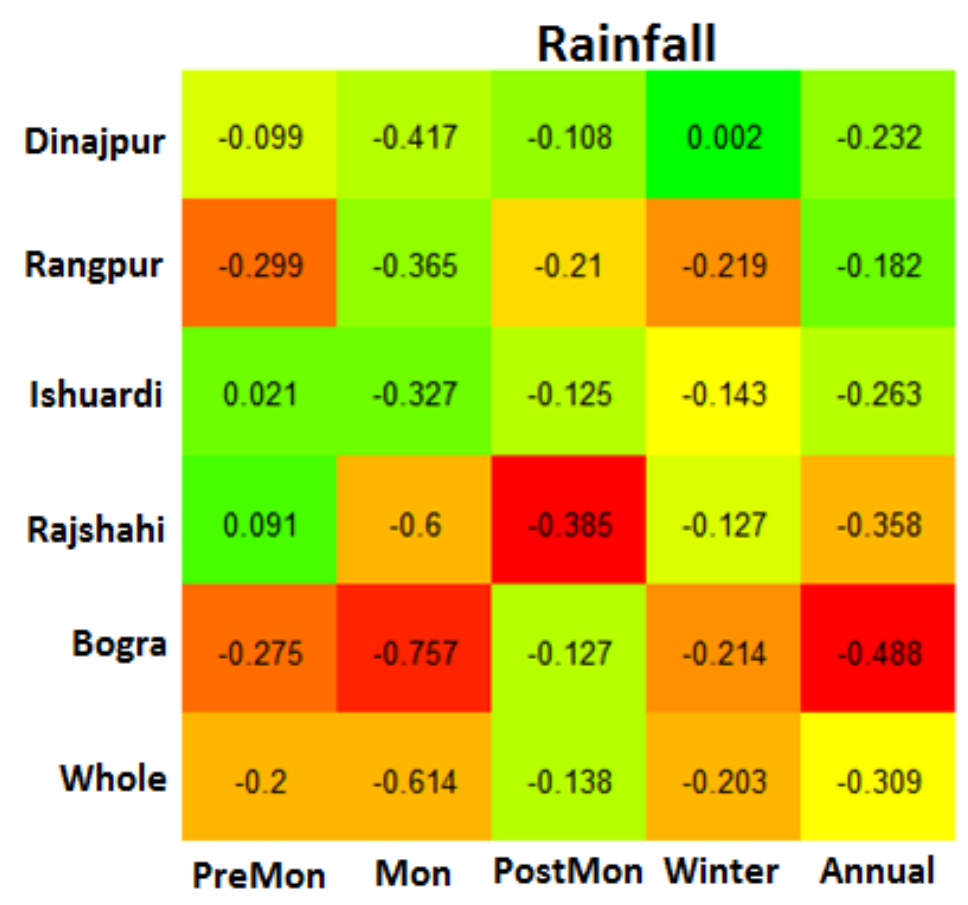

(a)

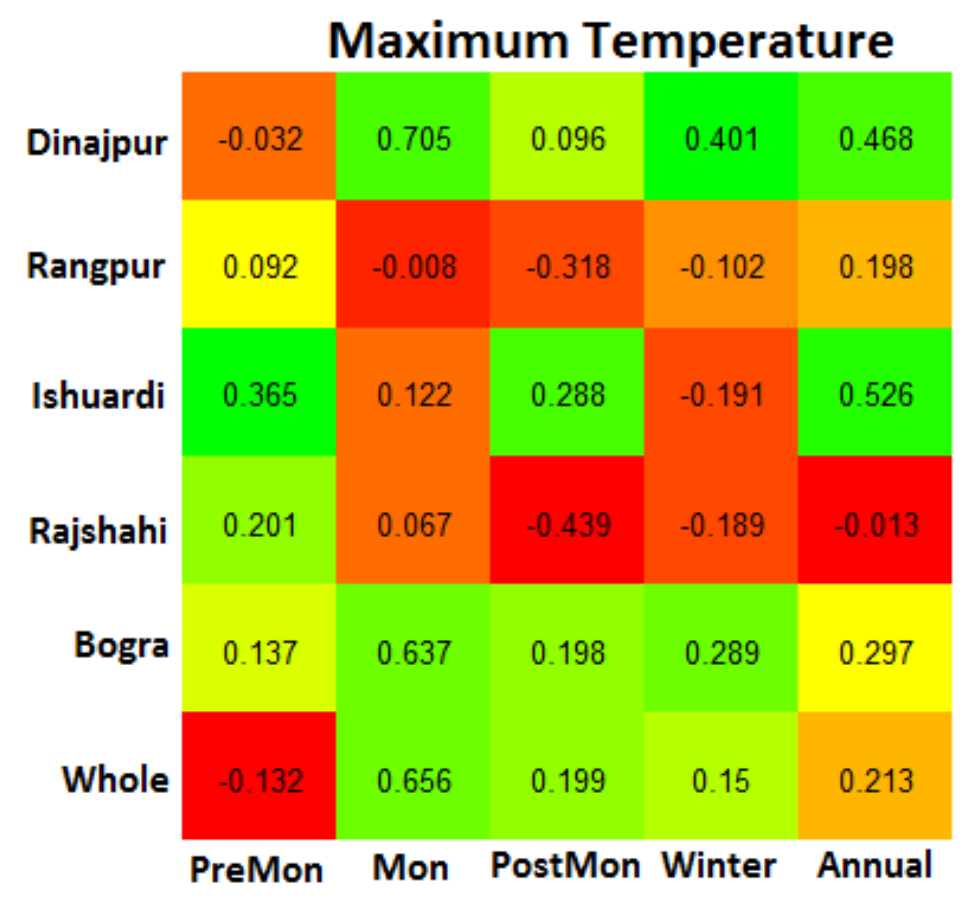

(b)

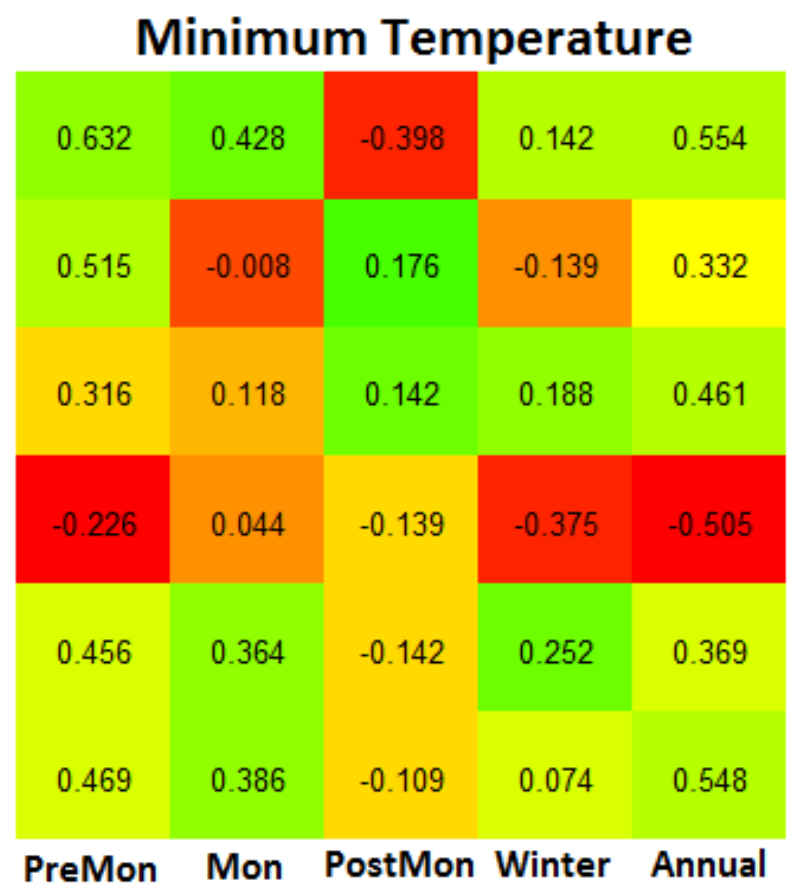

(c)

\section{Figure 8}

Spearman correlation of annual and seasonal NDVI with (a) rainfall; (b) maximum temperature; and (c) minimum temperature at five meteorological stations of northwest Bangladesh for the period 1982-2018 


\begin{tabular}{|c|c|c|c|c|c|c|}
\hline \multirow[b]{2}{*}{ Jan } & \multicolumn{6}{|c|}{ Dinajpur } \\
\hline & 0.11 & 0.032 & 0.111 & 0.231 & 0.118 & 0.223 \\
\hline Feb & 0.233 & .0 .179 & -0.121 & 0.136 & 0.079 & 0.353 \\
\hline Mar & -0.118 & .0 .192 & -0.395 & -0.174 & -0.327 & -0.321 \\
\hline Apr & 0.097 & -0.018 & -0.11 & 0.193 & 0.102 & -0.088 \\
\hline May & 0.122 & 0.263 & 0.175 & 0.183 & 0.264 & 0.191 \\
\hline Jun & -0.015 & .0 .069 & 0.101 & -0.07 & 0.006 & -0.015 \\
\hline Jul & -0.212 & 0.252 & .0 .076 & -0.053 & -0.083 & -0.068 \\
\hline Aug & -0.166 & .0 .182 & -0.269 & -0.255 & -0.452 & .0 .43 \\
\hline Sep & -0.006 & -0.151 & -0.093 & -0.058 & -0.129 & -0.167 \\
\hline Oct & 0.123 & -0.135 & -0.073 & -0.069 & -0.077 & -0.134 \\
\hline Nov & 0.353 & 0.252 & 0.108 & 0.385 & 0.31 & 0.427 \\
\hline Dec & -0.226 & 0.501 & 0.299 & 0.48 & 0.555 & 0.337 \\
\hline
\end{tabular}

\begin{tabular}{|c|c|c|c|c|c|}
\hline \multicolumn{6}{|c|}{ Rangpur } \\
\hline 0.199 & 0.076 & 0.005 & 0.169 & 0.012 & 0.349 \\
\hline 0.138 & -0.37 & .0 .24 & .0 .054 & -0.155 & 0.126 \\
\hline-0.141 & -0.123 & .0 .435 & .0 .219 & -0.338 & .0 .36 \\
\hline 0.024 & -0.051 & 0.005 & 0.024 & 0.006 & -0.11 \\
\hline 0.048 & 0.223 & 0.22 & 0.11 & 0.143 & 0.104 \\
\hline 0.131 & -0.167 & 0.14 & -0.047 & 0.016 & -0.001 \\
\hline-0.166 & 0.158 & -0.032 & -0.021 & -0.042 & -0.068 \\
\hline-0.103 & -0.232 & 0.077 & -0.191 & -0.166 & -0.246 \\
\hline 0.123 & -0.218 & -0.001 & -0.087 & -0.007 & -0.021 \\
\hline 0.131 & -0.138 & -0.126 & -0.03 & -0.092 & -0.149 \\
\hline 0.426 & -0.084 & 0.025 & 0.156 & 0.07 & 0.068 \\
\hline-0.006 & 0.405 & 0.065 & 0.361 & 0.275 & 0.131 \\
\hline
\end{tabular}

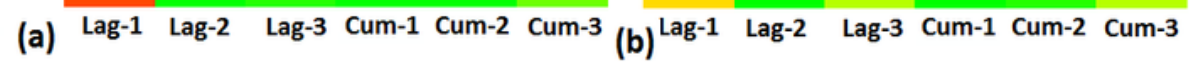

\begin{tabular}{|c|c|c|c|c|c|c|}
\hline \multirow[b]{2}{*}{ Jan } & \multicolumn{6}{|c|}{ Ishuardi } \\
\hline & .0 .028 & 0.235 & -0.063 & 0.187 & 0.027 & 0.045 \\
\hline Feb & 0.059 & -0.194 & -0.199 & .0 .085 & .0 .228 & 0.247 \\
\hline Mar & -0.197 & -0.123 & -0.198 & .0 .208 & -0.21 & -0.193 \\
\hline Apr & 0.056 & -0.166 & 0.098 & -0.059 & -0.001 & 0.04 \\
\hline May & 0.228 & 0.337 & -0.062 & 0.214 & 0.24 & 0.272 \\
\hline Jun & -0.065 & 0.237 & 0.452 & 0.072 & 0.184 & 0.181 \\
\hline Jul & -0.032 & -0.09 & 0.263 & 0.013 & 0.032 & 0.002 \\
\hline Aug & .0 .38 & -0.178 & 0.009 & .0 .441 & -0.335 & -0.279 \\
\hline Sep & 0.025 & -0.409 & -0.038 & -0.31 & -0.404 & -0.432 \\
\hline Oct & 0.035 & 0.14 & -0.198 & -0.013 & -0.104 & -0.1 \\
\hline Nov & 0.197 & -0.252 & 0.283 & -0.057 & -0.055 & -0.06 \\
\hline Dec & -0.04 & -0.047 & 0.071 & -0.106 & 0.077 & 0.208 \\
\hline
\end{tabular}

\begin{tabular}{|c|c|c|c|c|c|}
\hline \multicolumn{6}{|c|}{ Rajshahi } \\
\hline 0.148 & 0.19 & -0.085 & 0.043 & -0.084 & -0.057 \\
\hline 0.165 & -0.054 & -0.063 & -0.019 & -0.107 & 0.107 \\
\hline-0.206 & -0.028 & -0.242 & -0.117 & -0.222 & -0.337 \\
\hline 0.043 & -0.205 & 0.095 & -0.04 & 0.02 & -0.037 \\
\hline 0.193 & 0.102 & 0.005 & 0.214 & 0.215 & 0.246 \\
\hline 0.172 & 0.203 & 0.296 & 0.222 & 0.299 & 0.295 \\
\hline-0.273 & -0.114 & 0.074 & -0.346 & -0.262 & -0.236 \\
\hline-0.091 & -0.237 & 0.011 & -0.293 & -0.238 & -0.222 \\
\hline .0 .263 & .0 .324 & -0.224 & -0.351 & .0 .423 & -0.432 \\
\hline-0.226 & .0 .065 & .0 .034 & -0.292 & -0.331 & -0.328 \\
\hline 0.082 & -0.114 & -0.018 & 0.001 & -0.127 & 0.003 \\
\hline-0.03 & -0.044 & 0.009 & -0.057 & -0.056 & -0.118 \\
\hline
\end{tabular}

(c) Lag-1 Lag-2 Lag-3 Cum-1 Cum-2 Cum-3

(d) Lag-1 Lag-2 Lag-3 Cum-1 Cum-2 Cum-3

Bogra

\begin{tabular}{|c|c|c|c|c|c|c|}
\hline Jan & 0.276 & 0.283 & -0.01 & 0.325 & 0.048 & 0.128 \\
\hline Feb & 0.017 & -0.043 & 0.05 & -0.064 & 0.02 & 0.115 \\
\hline Mar & -0.12 & 0.006 & -0.49 & -0.075 & -0.172 & -0.114 \\
\hline Apr & -0.156 & -0.02 & 0.194 & -0.054 & 0.03 & -0.013 \\
\hline May & 0.207 & 0.067 & -0.012 & 0.191 & 0.254 & 0.25 \\
\hline Jun & 0.043 & 0.101 & .0 .048 & 0.008 & .0 .003 & -0.002 \\
\hline Jul & -0.491 & 0.173 & 0.059 & -0.359 & -0.374 & -0.367 \\
\hline Aug & -0.335 & -0.418 & -0.006 & -0.47 & -0.443 & -0.427 \\
\hline Sep & -0.152 & -0.331 & -0.368 & -0.259 & .0 .436 & -0.481 \\
\hline Oct & -0.021 & -0.221 & .0 .445 & -0.211 & .0 .413 & .0 .44 \\
\hline Nov & 0.332 & -0.17 & -0.02 & 0.063 & 0.062 & 0.018 \\
\hline Dec & 0.111 & 0.399 & 0.17 & 0.387 & 0.37 & 0.308 \\
\hline
\end{tabular}

(e) Lag-1 Lag-2 Lag-3 Cum-1 Cum-2 Cum-3

\section{Figure 9}

Spearman correlation of NDVI of each month with rainfall of different lags and cumulations at five meteorological stations of northwest Bangladesh for the period 1982-2018 


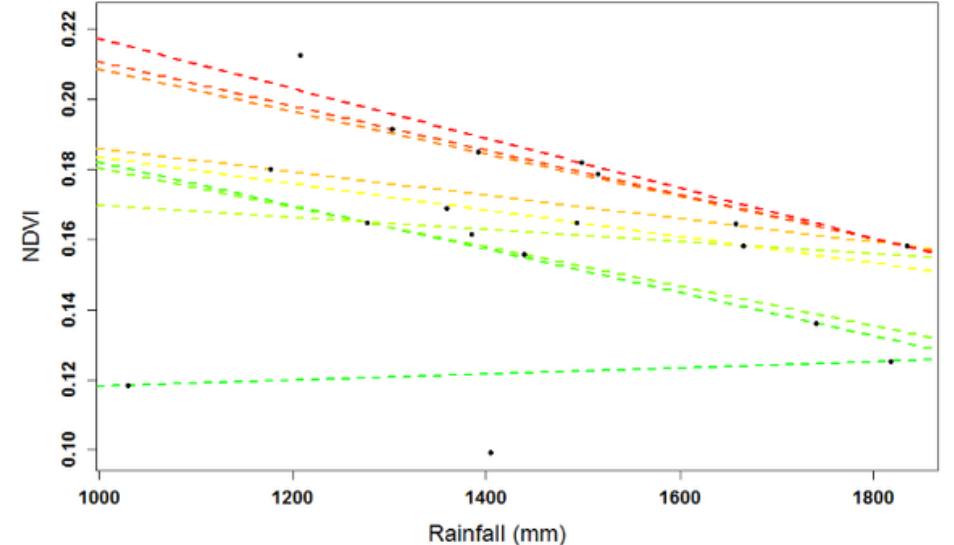

(a)

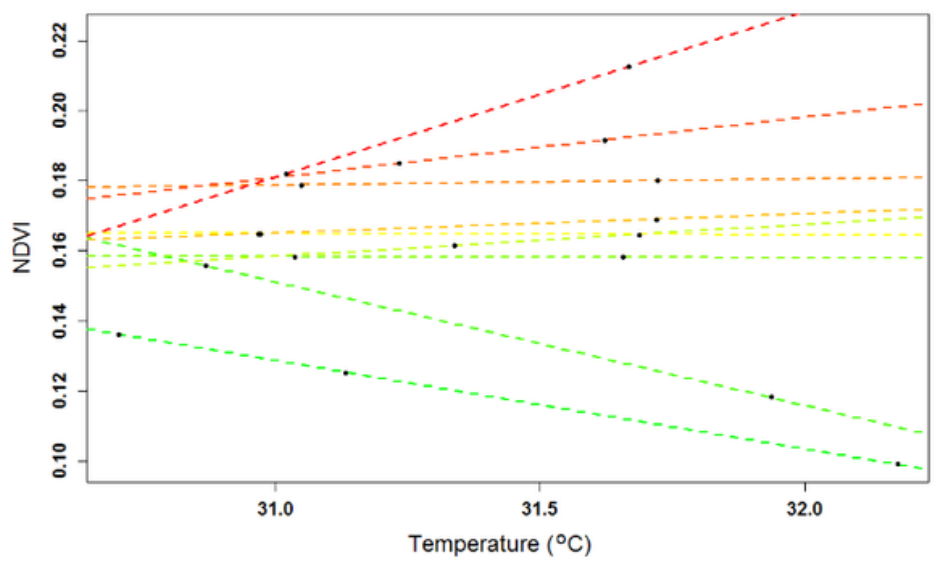

(c)

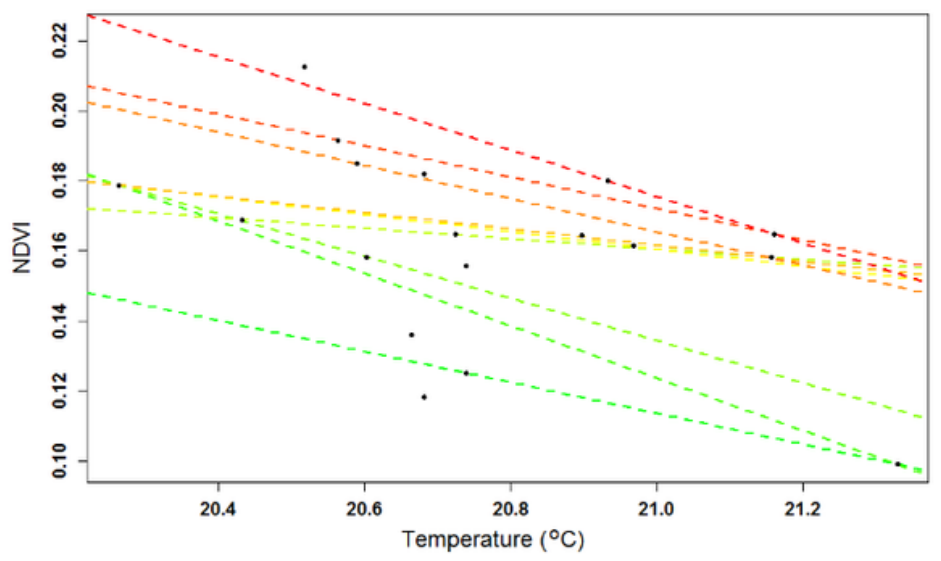

(e)

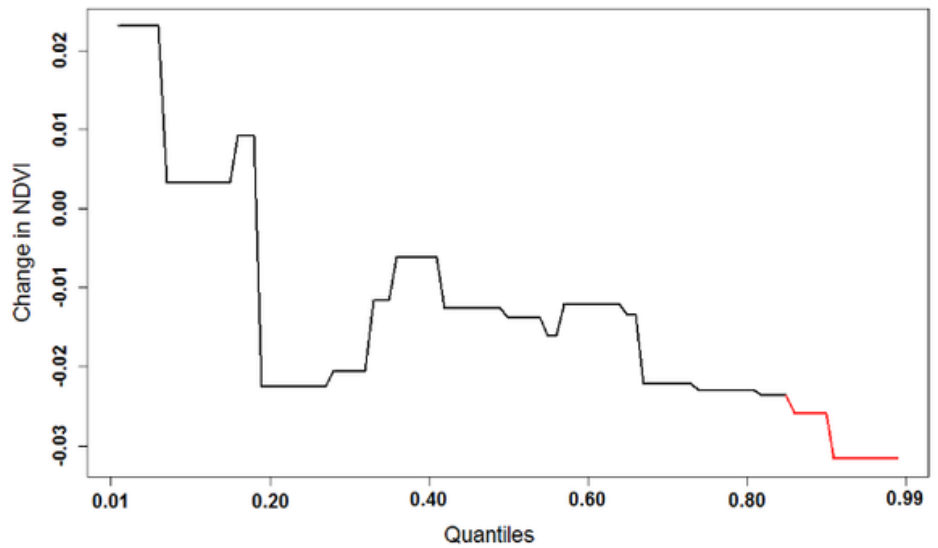

(b)

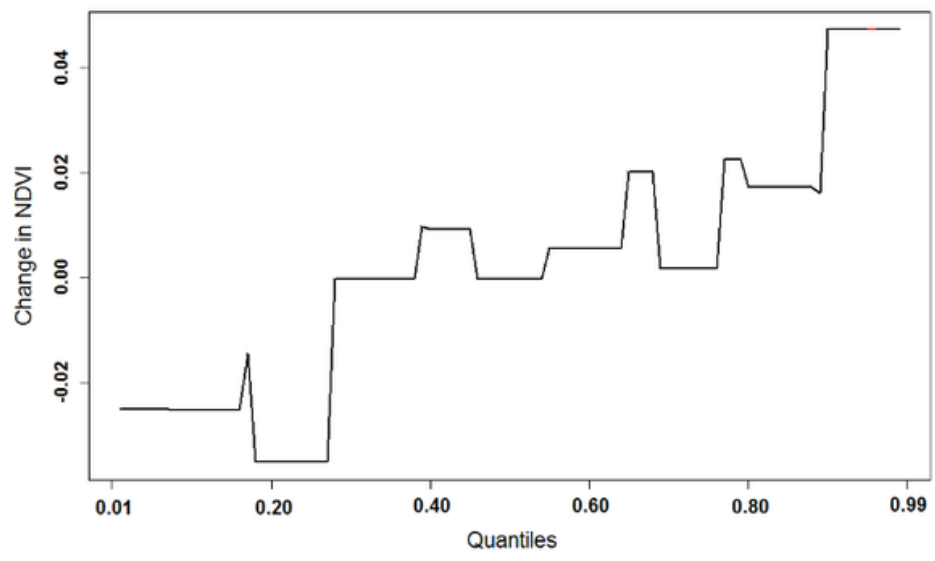

(d)

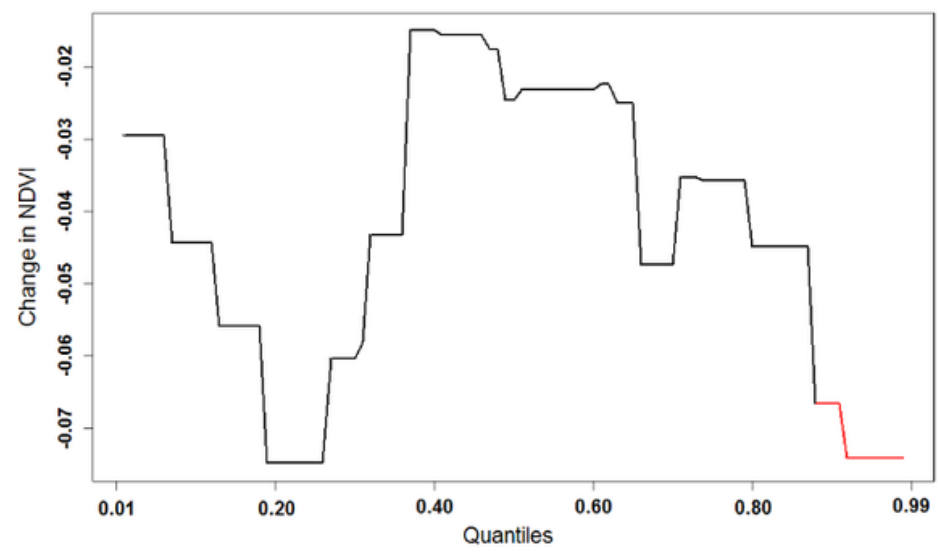

(f)

Figure 10

Relationship of NDVI with (a) rainfall, (b) maximum temperature, and (c) minimum temperature for 0.1 to 0.9 quantiles; the significance of the relationship between NDVI and (a) rainfall (a) rainfall, (b) maximum temperature, and (c) minimum temperature for 0.01 to 0.99 quantiles during 1982-2018 at Rajshahi station 


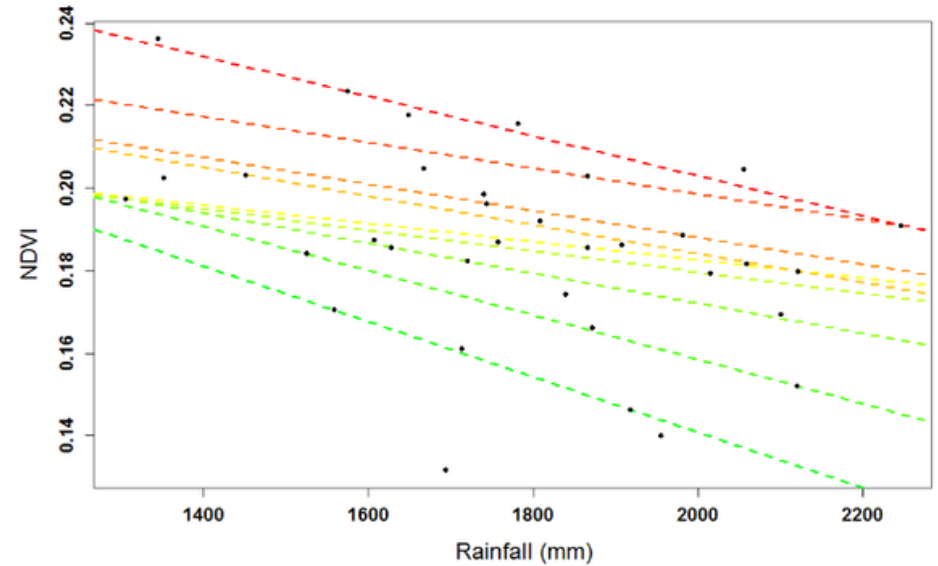

(a)

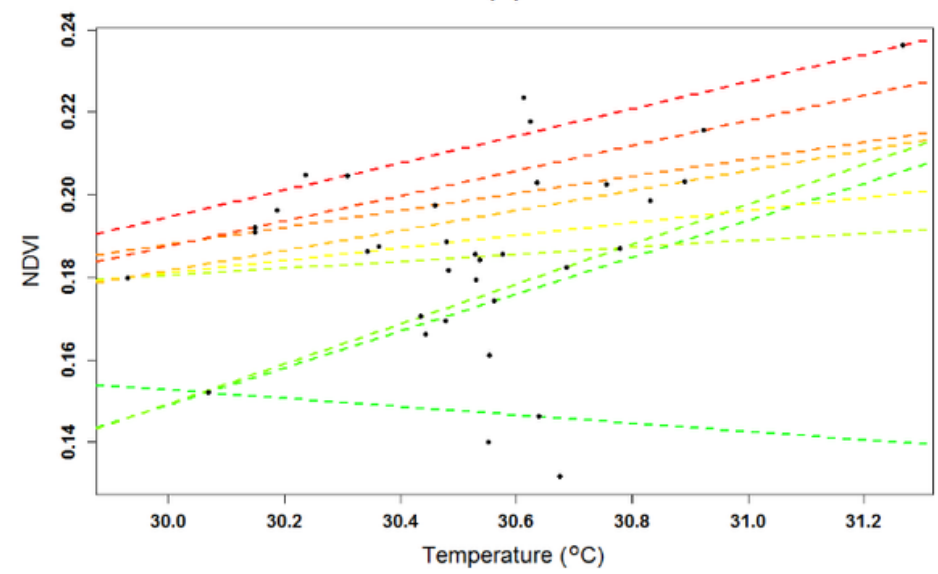

(c)

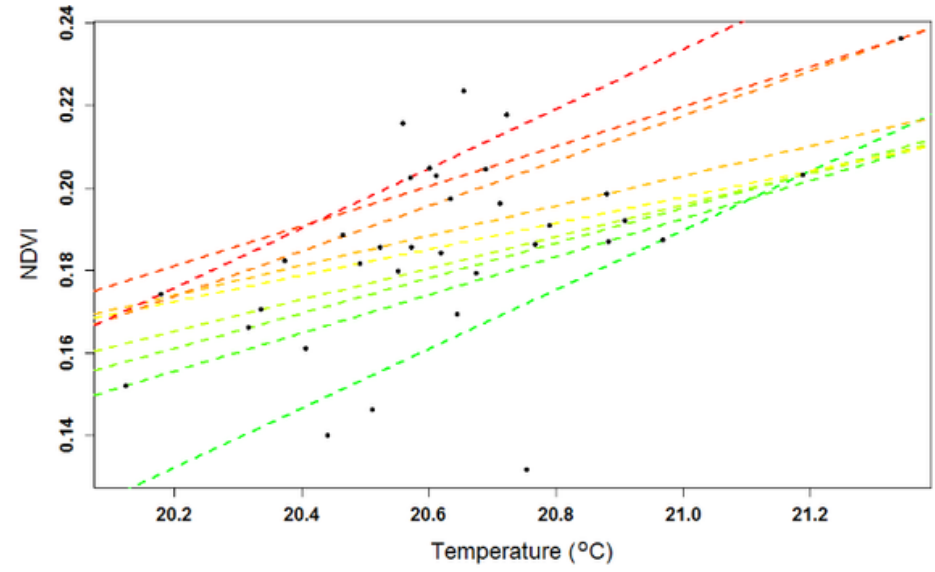

(e)

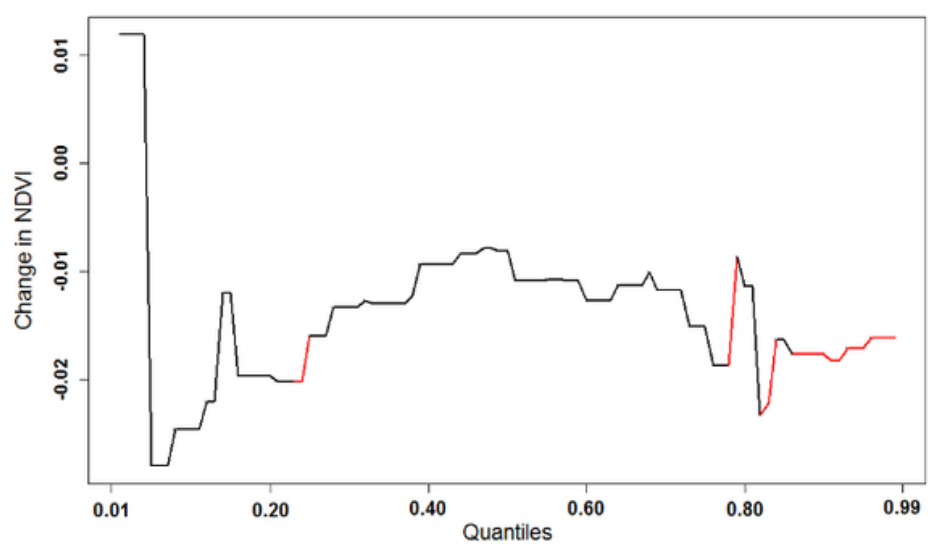

(b)

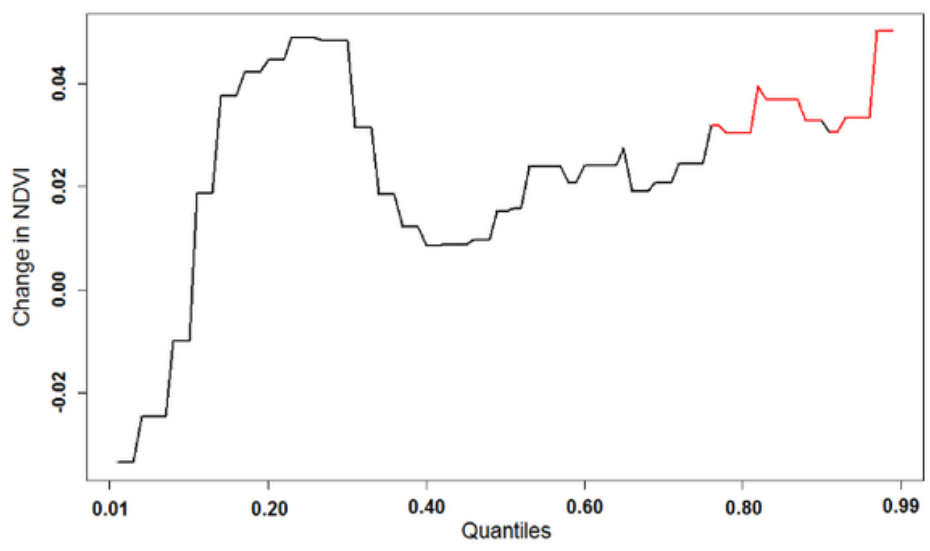

(d)

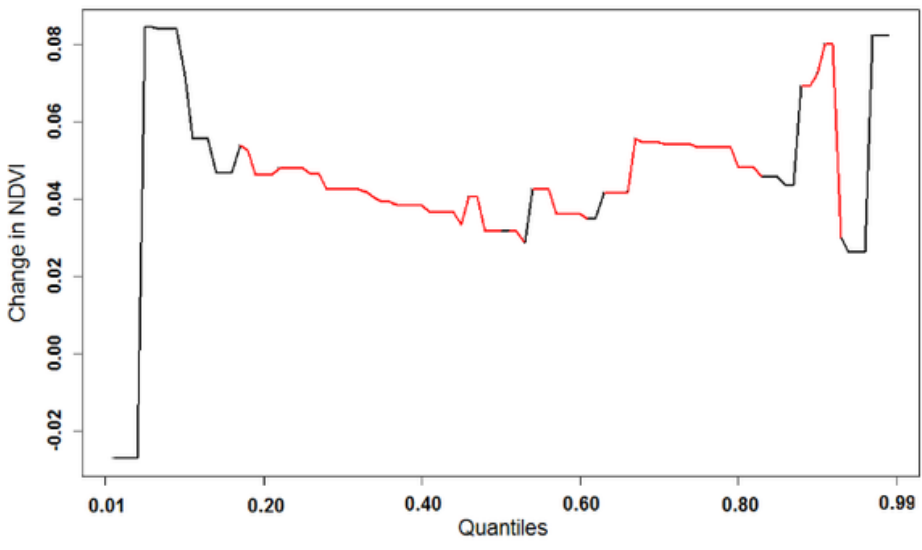

(f)

\section{Figure 11}

Relationship of NDVI with (a) rainfall, (b) maximum temperature, and (c) minimum temperature for 0.1 to 0.9 quantiles; the significance of the relationship between NDVI and (a) rainfall (a) rainfall, (b) maximum temperature, and (c) minimum temperature for 0.01 to 0.99 quantiles during 1982-2018 for the whole study area

\section{Supplementary Files}


This is a list of supplementary files associated with this preprint. Click to download.

- SupplementaryMaterials2.doc 